\title{
Sedimentary and egg-bank DNA from 3 European lakes reveal concurrent changes in the composition and diversity of cyanobacterial and Daphnia
}

\section{communities}

(Published in Hydrobiologia (2017) 800: 155-172, doi 10.1007/s10750-017-3247-7)

Marie-Eve Monchamp*1,2, Ioana Enache ${ }^{1,3,4}$, Patrick Turko ${ }^{1}$, Francesco Pomati ${ }^{1,2}$, Geta Rîşnoveanu ${ }^{4}$, Piet Spaak ${ }^{1,2}$

${ }^{1}$ Eawag, Swiss Federal Institute of Aquatic Science and Technology, Department of Aquatic Ecology, Dübendorf, Switzerland;

${ }^{2}$ Institute of Integrative Biology, Swiss Federal Institute of Technology (ETH) Zürich, Switzerland;

${ }^{3}$ Institute of Biology Bucharest, Department of Ecology, Taxonomy and Nature Conservation, Romanian Academy, Bucharest, Romania;

${ }^{4}$ University of Bucharest, Faculty of Biology, Department of Systems Ecology and Sustainability, Doctoral School in Ecology, Bucharest, Romania;

*Corresponding author:

Phone: $+41(0) 587656728$

E-mail: Marie-Eve.Monchamp@eawag.ch

Kywords: Long-term change, eutrophication, microsatellite genotyping, high-throughput amplicon sequencing, Danube Delta, pre-alpine lakes.

This document is the accepted manuscript version of the following article: Monchamp, M. E., Enache, I., Turko, P., Pomati, F., Rîşnnoveanu, G., \& Spaak, P. (2017). Sedimentary and egg-bank DNA from 3 European lakes reveal concurrent changes in the composition and diversity of cyanobacterial and Daphnia communities. Hydrobiologia, 800, 155-172. 


\begin{abstract}
Eutrophication generally favours the growth of cyanobacteria over eukaryotic green algae in freshwater lakes. Cyanobacteria constitute a poor food source for the waterflea Daphnia, an important primary consumer of phytoplankton in lakes. While it is known that some Daphnia species are adapted to eutrophic conditions and can cope with cyanobacteria in their diet, it is less known whether cyanobacterial community composition can influence Daphnia population structure in lakes. We studied the variation in genetic diversity of Daphnia resting eggs and cyanobacterial DNA preserved in sediment cores from three European lakes impacted by eutrophication. Our retrospective analysis confirms that D. galeata invaded the two pre-alpine lakes around the middle of the twentieth century, hybridized with and became dominant over D. longispina. This coincides with the presence in all lakes and the increase in the proportion of colonial and filamentous cyanobacteria in the pre-alpine lakes. The recent reoligotrophication of the lakes did not reverse the cyanobacterial and Daphnia assemblages to their pre-eutrophication composition and genetic structure, suggesting that both changed irreversibly due to anthropogenic influence on the ecosystems. Genetic analyses applied to lake sedimentary archives have the potential to unveil how different compartments of the food-web co-vary in a changing environment.
\end{abstract}




\section{Introduction}

A majority of lakes have been impacted by human-induced eutrophication (i.e., the overenrichment by nutrients) over the past century (Schindler 2012; Smith 2003), with negative consequences on water quality and on ecosystem processes (Smith et al. 2006; Sukenik et al. 2015). In Europe, most lakes underwent a major phase of eutrophication around the middle of the twentieth century that was in most cases followed by a re-oligotrophication phase due to targeted reduction of phosphorus loading (Anneville et al. 2005; Vonlanthen et al. 2012). Reoligotrophication generally led to improved water quality and ecosystem functioning by alleviating symptoms of eutrophication, such as deep-water oxygen depletion that affects fish survival, and low autotroph to herbivores energy transfer efficiency characteristic of cyanobacteria-dominated phytoplankton communities (Bürgi et al. 2003; Müller et al. 2014; von Ellert et al. 2003). The long-term effects of eutrophication followed by re-oligotrophication on the genetic structure of plankton communities, however, remain largely unknown. One of the first long-term $(100 \mathrm{yr})$ population genetic structure assessments of the impact of eutrophication showed that the composition and genetic diversity of populations of the waterflea Daphnia underwent permanent changes attributable to eutrophication (Brede et al. 2009). Similarly, long-term changes (over $100 \mathrm{yr}$ ) in diversity of Synechococcus (picocyanobacteria) populations in a deep pre-alpine lake have been linked to the lake's trophic status, and revealed a similar phylogenetic composition during the periods of preeutrophication and re-oligotrophication (Domaizon et al. 2013).

Daphnia (Crustacea: Anomopoda) is ecologically important because of its dual role as a primary consumer of phytoplankton and an important food for fish (Lampert 2006), thus occupying a central position in many lentic food webs. Daphnia dominates the zooplankton community and often reaches high densities in many lakes and ponds worldwide. Under harsh conditions (e.g., food limitation, cooling), Daphnia reproduces sexually, producing haploid sexual eggs. These eggs are contained in a sclerotized sac (ephippium), which often sink to the sediments, from which they may hatch the following spring or be buried. Buried eggs may preserve their DNA intact and remain viable for decades (e.g., Turko et al. 2016) or even centuries (Frisch et al. 2014), making it possible to use them to investigate changes in the genetic structure of Daphnia populations over long time-scales (Brede et al. 2009; Kerfoot et al. 1999; Turko et al. 2016).

The Daphnia longispina-galeata-cucullata complex is one of the most prevalent in European lakes (Schwenk and Spaak 1995; Petrusek et al. 2008a). Both interspecies 
hybridisation and introgression within the complex are known, and members are differentially adapted to environmental conditions (Flößner 2000; Petrusek et al. 2008b; Schwenk et al. 2000). Due to this local adaptation to a variety of conditions, combined with the excellent dispersal ability of ephippia (Bohonak and Jenkins 2003), environmental change has the potential to dramatically alter the ranges of Daphnia species. Human-induced eutrophication of lakes has been identified as a main cause of biological invasions by species of the genus Daphnia in Europe and elsewhere (Moest et al. 2015; Brede et al. 2009; Weider et al. 1997). One documented example is the invasion by Daphnia galeata of several European pre-alpine lakes during the period of maximal eutrophication in the 1960s and 1970s. This major event was followed by hybridisation with native species and subsequent introgression, leading to drastic changes in the genetic composition of local Daphnia populations (Alric et al. 2016; Brede et al. 2009; Rellstab et al. 2011).

One main consequence of the eutrophication process is that it favours primary productivity of phytoplankton, especially of cyanobacteria (Paerl et al. 2001). Changes in environmental conditions (such as fluctuations in nutrient concentrations) influence cyanobacterial abundance, but also its taxonomic composition in lakes (Rigosi et al. 2014). Warming and over-enrichment of nutrients are important factors facilitating the global expansion of cyanobacteria, especially "invasive" taxa in the orders Chroococcales and Nostocales (Reviewed in Sukenik et al. 2015). The latter two groups comprise taxa that have eco-physiological traits, like buoyancy regulation, that allow them to thrive in light depleted and highly competitive environments (Carey et al. 2012). While some of these range shifts in response to environmental change have been documented, little information is available about the long-term genotypic population structure changes of Daphnia populations and its consequences for the food-web.

In this study, we seek to trace the genetic histories of several Daphnia populations during and after human-induced eutrophication, a period that was characterized by the dominance of cyanobacteria in the phytoplankton community. Cyanobacteria have long been known to be a poor food source for zooplankton in general, (Lampert 1987) for various reasons. They lack essential nutrients needed by zooplankton (von Elert et al. 2003), large colonies interfere with the feeding apparatus of Daphnia, and although smaller filaments or colonies pieces can be ingested, they might be poorly digested or assimilated. Further, some strains of cyanobacteria can produce toxic compounds, which can affect Daphnia reproduction and survival (Drugă et al. 2016; Rohrlack et al. 1999). The microcystins form the most common group of cyanotoxins observed in temperate lakes (Chorus and Bartram 1999). They are 
synthesized mainly by colonial and bloom-forming cyanobacteria of the genera Microcystis, Planktothrix, and Dolichospermum (formerly called Anabaena), which often dominate phytoplankton communities in productive lakes. Thus, knowing about the cyanobacterial species composition and the presence of microcystins-producing strains in natural lake communities is important for understanding the interaction between Daphnia and cyanobacteria.

Daphnia - cyanobacteria interactions have been extensively discussed in the literature, but much of the findings have been contradictory (Ger et al. 2016; Lemaire et al. 2012). Genotype $\times$ genotype interactions might explain some of the contradicting results reported, as it appears that certain Daphnia genotypes are better adapted than others to local conditions (including cyanobacterial presence). For example $D$. cucullata have been shown to have a competitive advantage over other Daphnia in the presence of filamentous cyanobacteria (Gliwicz and Lampert 1990), which contribute to their success in eutrophic lakes. Lemaire et al (2012) found that the reaction of daphnids to cyanobacteria depended not only on the origin of the Daphnia clone, but also on the lake or pond from which the cyanobacteria strain originated. The physiological sensitivity of zooplankton taxa to microcystins has also been shown to differ (DeMott et al. 2001). These results suggest that Daphnia are capable of evolving adaptive mechanisms to cope with cyanobacteria. This suggestion has been experimentally confirmed using the "resurrection ecology" (Kerfoot et al. 1999) approach on the dormant egg bank (Hairston et al. 2001; Hairston et al. 1999; Jiang et al. 2016).

Palaeolimnological reconstructions are useful to track compositional (species) and genetic changes in plankton assemblages. Daphnia populations have been successfully reconstructed from lakes sedimentary egg bank (Ishida et al. 2012; Limburg and Weider 2002; Turko et al. 2016) over long time scales. Similarly, DNA preserved in lacustrine sediments (sedimentary DNA) was also used to track long-term changes in the diversity of a broad range of pelagic organisms, such as cyanobacteria (e.g., Monchamp et al. 2016; Savichtcheva et al. 2011), eukaryotic algae (Hou et al. 2014; Stoof-Leichsenring et al. 2012), protists (Capo et al. 2016), and zooplankton (Bissett et al. 2005). Here, using sedimentary and egg-bank DNA, we aimed at identifying trends in taxonomic and genetic diversity of Daphnia and cyanobacteria, and at determining whether shifts in community composition happened at the same time at two levels of the food web. For this, we reconstructed 1) the taxonomic and genetic diversity in Daphnia populations from the sedimentary egg bank using microsatellites, and 2) the 
taxonomic and phylogenetic diversity of cyanobacteria (including potentially toxic strains) by sequencing DNA preserved in sediment cores of three lakes dating back $\sim 60$ to 80 years.

\section{Material and Methods}

\section{Lake characteristics}

A summary of the main characteristics of the three lakes is available in Online Resource 1 in the Supporting Information. The lakes were chosen because the structure of their sedimentary archive showed potential for dating. In addition, the two pre-alpine lakes have been well studied and the history of eutrophication of these lakes is known. For the third lake located in Eastern Europe, no long-term data was available, and little is known about the timing and the strength of the human-mediated eutrophication.

Lake Gorgova (long. 45.15, lat. 29.18; surface area $13.8 \mathrm{~km}^{2}$ ) is located in the Danube Delta (Romania), which is the end point of the Danube River and its connection to the Black Sea. The Delta comprises of hundreds of lakes, all of which are interconnected to different degrees to each other or to the main branches of the Danube River (Oosterberg et al. 2000). Gorgova is a relatively shallow lake (maximum depth $\sim 3 \mathrm{~m}$ ), but because of its connection with the main river, its water level fluctuates seasonally. The lake is completely mixed several times per year due to the dominant winds in the region and the shallow depth of the lake. With a concentration of total phosphorus (TP) of $26 \mu \mathrm{g} / 1$ measured over the water column in spring 2015, the lake classifies as meso-eutrophic (OECD 1982). The lake floor is covered with high densities of the submerged macrophytes Potamogeton sp. (Oosterberg et al. 2000; This study).

Lake Greifensee (long. 47.34, lat. 8.68) is located $20 \mathrm{~km}$ east of the city of Zurich, north of the Swiss Alps. It has a surface area of $8.5 \mathrm{~km}^{2}$ and a maximum depth of $33 \mathrm{~m}$. The lake is eutrophic (annual mean TP concentration around $40 \mu \mathrm{g} / \mathrm{l}$ ) and is completely mixed once every winter. The phosphorus concentration in the lake has been monitored on a monthly basis over the past six decades, and the lake is known for presenting regular blooms of Microcystis species (Monchamp et al. 2016).

Lake Hallwil (Hallwilersee; long. 47.28, lat. 8.21) is another pre-alpine lake located about $65 \mathrm{~km}$ west of Greifensee. Its size $\left(10 \mathrm{~km}^{2}\right)$ and maximum depth $(46 \mathrm{~m})$ are similar to Greifensee, but the lake is meso-eutrophic (mean annual TP concentration around $18 \mu \mathrm{g} / \mathrm{l}$ ). Hallwilersee also differs from Greifensee with respect to water mixing: because of the presence of relatively high hills around the lake, the winds are not sufficient to trigger natural mixing of 
the lake, even though the spring and autumn thermal conditions are adequate (Liechtli 1994). The chemical characteristics of Hallwilersee have been monitored for five decades, and the presence of the potentially harmful cyanobacterium Planktothrix rubescens in the lake has been reported since the 1880s (Züllig 1982).

Both pre-alpine lakes underwent a major phase of eutrophication around the mid twentieth century, caused by massive inputs of phosphorus to the lakes as a consequence of the increasing agriculture and urban development activities in the watershed from the 1950s onward (Liechtli 1994). Governmental efforts to control pollution by phosphorus (installation of wastewater treatment plants, ban of phosphorus in detergents) helped reduce phosphorus concentrations in most lakes of the region since the end of the 1980s. In addition to these measures, the authorities of Hallwilersee started to mechanically aerate the bottom of the lake in 1986 (Stöckli 2010) to help reduce the release of phosphorus from the sediments. Although there are no long-term records of the water chemistry in Lake Gorgova, it is known that the general water quality in the Danube Delta has severely degraded over the past few decades as a consequence of increased pollution, both locally and along the Danube River (reviewed in Oosterberg et al. 2000). The human-induced changes in the Danube Delta wetlands over the second half of the twentieth century (e.g., man-made channelization, fisheries) and the nutrientpolluted Danube river waters that feed the Delta have accelerated eutrophication (Cristofor et al. 1993). Overall in the Delta, the period of maximal eutrophication was recorded during the second half of the 1980s (Vădineanu et al. 1992), when concentrations of total reactive phosphorus were as high as $200 \mu \mathrm{g} / \mathrm{l}$ in some lakes (Rîșnoveanu et al., 2004). After 1990, the economic collapse in the Danube river basin helped reduce phosphorus concentration in both the Danube river waters and the lakes in the Delta.

\section{Sediment sampling, description, and dating}

In Lake Gorgova, three sediment cores of 24 to $34 \mathrm{~cm}$ in length were collected from the centre of the lake in May 2015 using a gravity corer equipped with PVC tubes of $63 \mathrm{~mm}$ in diameter. The cores were sealed and kept in a cool and dark place until they were transported back to Eawag (Dübendorf, Switzerland) where they were stored at $4^{\circ} \mathrm{C}$ in a vertical position until opening. Sediment cores (63 mm diameter) were collected from the centre of lakes Greifensee in June 2013 and Hallwilersee in 2012 and 2014 using an EAWAG-63/S gravity corer. These sediment cores were preserved as previously described until they were opened and all cores were processed within few weeks after sampling. 
The sediment cores were sliced longitudinally using large brass blades. The sediments were photographed immediately, allowed to oxidize at $4^{\circ} \mathrm{C}$ in the dark for 24 hours to improve contrasts, and photographed again. The longest core from Lake Gorgova (34 cm) was used for sediment dating. Briefly, the sediments layers were sampled at $1-\mathrm{cm}$ intervals in one half of the sediment core using sterile blades. The samples were transferred to plastic boxes and were stored at $-20^{\circ} \mathrm{C}$ overnight before they were freeze-dried for 48 hours. The dried samples were then crushed, and all coarse particles (e.g., mollusc shells) were removed. The homogenized sediments were weighted into plastic tubes for gamma spectrometry measurements $\left({ }^{7} \mathrm{Be},{ }^{137} \mathrm{Cs}\right.$, ${ }^{210} \mathrm{~Pb}$ ) on a high-purity germanium (HPGe) well detector (Canberra Industries). The ${ }^{137} \mathrm{Cs}$ and ${ }^{210} \mathrm{~Pb}$ isotopes are useful to accurately date sediments back to the $1950 \mathrm{~s}$ and to estimate sedimentation rate. Because of its very short half-life ( $\sim 53$ days), ${ }^{7} \mathrm{Be}$ can be used to verify the presence of the surface sediments in the core (up to $\sim 1$ year). For the two pre-alpine lakes, the sediment cores were previously dated based on ${ }^{137} \mathrm{Cs},{ }^{210} \mathrm{~Pb}$, and varve counts (Monchamp et al. in prep; Monchamp et al. 2016). The recent sediments ( 75 years) of Greifensee and Hallwilersee are characterized by the presence of annual laminations (varves) that formed as a consequence of high primary productivity and oxygen depletion in the deep-water layers in the two lakes. The age of the sediments is relatively easy to determine based upon these annual varves that are composed of a pale layer corresponding to spring/summer, and a dark layer that forms during winter (Zolitschka 2007).

\section{Sediment core preparation for ephippia extraction}

After dating, we used our core photographs to apply the age model to the cores from which we retrieved Daphnia eggs. For lakes Greifensee and Hallwilersee, where annual varves are visible, we sampled the sediment cores by slicing 1 or 2-year sections with acid-washed zinc blades. For Lake Gorgova, the temporal resolution provided by the age model was lower; therefore we cut layers of $1-\mathrm{cm}$, which generally corresponds to a 2 to 3 -year period. In Greifensee, four time periods were chosen (1956-57, 1966-67, 1974-75, and 2003-04) to capture the time of intense cultural eutrophication, which resulted in rapid Daphnia community composition changes (Brede et al. 2009), and one more recent time period after reoligotrophication. Similarly, we sampled the Hallwilersee sediments for the years 1950, 1960, 1970, and 2000. In Lake Gorgova, we did not have prior knowledge on the exact timing or the extent of the eutrophication and re-oligotrophication periods, therefore we chose to sample sediments layers (sixteen in total) at high temporal resolution spanning between the mid-1950s 
and 2015. These sediment sections were passed through a clean $150 \mu \mathrm{m}$ brass sieve, and the remnants were examined under a stereomicroscope at $20 \times$ magnification to pick out the Daphnia ephippia. The ephippia were counted, individually placed in a drop of water, and opened with flame-sterilized dissection needles. The eggs were removed and transferred into $200 \mu \mathrm{l}$ tubes containing $25 \mu \mathrm{l}$ alkaline lysis buffer for DNA extraction as described below. In case an egg broke during handling, only the broken egg was kept, as we considered the unbroken egg to probably be contaminated. Although the two eggs from each ephippium have the same mother and cannot be considered fully independent, we chose to analyze both, for two reasons. First, as our goal was reconstruct the population as it existed in nature, we sampled the egg bank as fully as possible. All of the eggs would have contributed to the next generation, had they hatched. Second, as the eggs are produced sexually, each of them should represent different genotypes. The DNA was extracted from these eggs following the HoTShot protocol (Montero-Pau et al. 2008) and stored at $-20^{\circ} \mathrm{C}$ until use. The eggs were genotyped using microsatellites as detailed below.

\section{Microsatellite genotyping and analysis}

For assessing the genetic diversity of the Daphnia egg banks in the three lakes, we amplified a panel of 8 microsatellite markers in an optimized multiplex protocol (DaB10/14, Dp512, SwiD1, SwiD10, SwiD12, SwiD14, SwiD4, and SwiD5; Brede et al. 2006). Because there was low genetic variation in Lake Gorgova, we added another eight microsatellite markers to the aforementioned ones in order to obtain greater resolution for taxa in the D. longispina complex. The markers were SwiD2, SwiD6, SwiD15, DaB17/17, Dp519, Dp281NB, Dgm105, and Dgm109 (Brede et al. 2006).

The microsatellite markers were analyzed on an ABI 3130 XL sequencer (Applied Biosystems), and the fragments length were inferred using the software STRand (Toonen and Hughes 2001) version 2.4.59 (http://www.vgl.ucdavis.edu/STRand) and binned into integer alleles using the R package 'MsatAllele' (Alberto 2009). The binned allele data were used for the determination of species identity via comparison with a panel of reference genotypes, which consisted of 57 D. galeata, 30 D. longispina, 31 D. cucullata, and 49 D. galeata $\times$ longispina hybrids that were collected in several lakes covering the northern and southern European perialpine area (Möst 2013). We supplemented this reference dataset by producing 50 random hybrids of D. cucullata with each of the other parental species, using the R package 'adegenet'. The real and simulated reference genotypes were used as a training set to derive a clustering 
procedure using Discriminant Analysis of Principal Components (DAPC, Jombart 2008). The derived discriminant functions were then applied to the samples to obtain a posterior probability of membership in each of the 6 modeled clusters ( 3 parental species and 3 hybrids). Clustering was based on a $>0.9$ probability. Complex hybrid classes (e.g., a hybrid in which at least one parent is also a hybrid) were inferred when membership probability was evenly split between two of the modeled clusters.

\section{Sedimentary DNA isolation for cyanobacterial analyses}

For cyanobacterial high-throughput amplicon sequencing, we used sediments collected at 1-cm intervals down the Gorgova core. Because of the laminated structure (presence of annual varves)of the sediments in Greifensee and Hallwilersee, and based on the existing highresolution age-depth models, we were able to sub-sample the cores at specific years with the goal to compare communities dated to similar time periods as the Daphnia populations. In both cores, we chose samples covering the periods of pre-, mid- and post-eutrophication. While subsampling the cores, we carefully avoided the sediments in contact with the plastic layer to reduce the risks of contamination with foreign DNA. Sediment samples were immediately transferred into sterile tubes, and carried to the Eawag clean lab facility for DNA extraction and further analyses. We performed the DNA extractions in batches of seven samples, plus a negative control (which contained all the reagents, but did not contain sediments). We followed strict environmental DNA work protocols at all steps to reduce the risks of contamination with external DNA. For Lake Gorgova, DNA extracts collected at each 1-cm layer were pooled in a total of eleven samples, each comprising 2 to 4 layers, to obtain a similar temporal resolution as used in the Daphnia dataset.

The forward and reverse PCR primers (Monchamp et al. 2016) specific to cyanobacteria were tagged with a 8 to 12 random nucleotides (nts) barcode, and used for amplifying a 400 nt-long section of the cyanobacterial 16S rDNA gene. The PCR reactions were performed in a final volume of $40 \mu 1$ containing $\sim 12$ ng template DNA (Monchamp et al. in prep). The PCR products were purified with the Illustra GFX PCR DNA and gel band purification kit (GE Healthcare, Chicago, USA), quantified using a Qubit fluorometer (Thermo Fisher Scientific) and pooled at equimolar concentration. The final library was sent to Fasteris (Geneva, Switzerland) for paired-end $2 \times 250$ bp sequencing on a MiSeq platform (Illumina Inc.). 
Sequence data processing and taxonomic determination of cyanobacterial operational taxonomic units (OTUs)

The workflow used for data quality control and processing is fully detailed in Monchamp et al. (2016). After primer trimming, quality filtering, size selection, and removal of samples containing less than 4,000 reads, a total of 2,177,896 sequences were obtained distributed in 26 samples ( 9 from each Lake Gorgova and Hallwilersee, 8 from Greifensee) and 2 negative controls. The negative controls each contained less than $0.01 \%$ of the average number of reads in the samples; therefore they were excluded. Cleaned amplicons were clustered into OTUs at the 0.03 similarity level and an abundance size threshold of 5 . The taxonomic assignment was done following UTAX (http://www.drive5.com/usearch/manual/utax_user_train.html). Only OTUs confidently assigned to photosynthetic cyanobacteria (based upon a confidence threshold of 0.85 ) were retained for analysis. The final dataset comprised 942 '812 sequence reads recovered from sediments dating back to years between 1928 and 2015.

\section{Detection of potentially microcystin-producing cyanobacteria}

For the detection of potentially microcystin-producing cyanobacteria in the sediments of Lake Gorgova and Hallwilersee, we followed the method described in (Monchamp et al. 2016) previously applied to the Greifensee sediment core. Briefly, a $\sim 400$-nt-long fragment of the mcyA gene specific to the genera Anabaena, Microcystis, and Planktothrix (Hisbergues et al. 2003) was amplified and the product was visualized on an agarose gel. The products were purified and directly Sanger-sequenced (Microsynth, Balgach, Switzerland). Each chromatogram was visually inspected, and sequences were aligned in Muscle (Edgar 2004). Unique sequences were used in a BLAST search against the GenBank genetic sequence database to determine the closest relative. We complemented our dataset with the published results from a previous study on the Greifensee sediments (Monchamp et al. 2016).

\section{Genetic and phylogenetic diversity analyses of Daphnia and cyanobacteria}

The Daphnia genotypic and the cyanobacterial OTU data were analysed using the software R (R Core Team 2013) with the help of various packages. Daphnia genetic differentiation between subpopulations separated in time was quantified using Jost's D (Jost 2008) as implemented in the package 'mmod' (Winter 2012) using our microsatellite markers. These statistics were used to create a genetic distance matrix for each lake, which was used in a nonmetric multidimensional scaling (NMDS) analysis in the package 'MASS' to visualize the 
genetic divergence between Daphnia populations from different time periods in individual lakes. We chose to classify the OTUs into 5 orders for visualizing the composition of cyanobacteria in our lakes, as the taxonomic resolution was low for some OTUs. For all cyanobacterial analyses, we used the OTU counts rarefied at the level of the sample with the lowest number of sequencing reads $(4,338)$. The principal component analysis (PCA) is based on the proportion of Daphnia taxa and the proportion of cyanobacterial orders recovered in each sample using standardized community values. Beta diversity between cyanobacterial communities of individual lakes over time was estimated using the package 'phyloseq' in Bioconductor (McMurdie and Holmes 2013). Similarly to the Daphnia analyses, two distance matrices between cyanobacterial OTUs based on phylogenetic relatedness (Unifrac distance; Lozupone and Knight 2005) and on taxonomic dissimilarities (Jaccard distance; Faith et al. 1987) were created in the package 'phyloseq'. The NMDS was applied to the phylogenetic distance matrix to visualize temporal beta diversity (i.e., within-lake dissimilarities over time).

\section{Results}

\section{Sediment age-depth models}

The ${ }^{137}$ Cs activity was generally low in Lake Gorgova, which makes difficult to accurately estimate years for this sediment core (Online Resource 2 in the Supporting Information). As a consequence, the dates used in the subsequent analyses and figures for Lake Gorgova should be interpreted with caution. ${ }^{137} \mathrm{Cs}$ activity was detected in the lower section of the Gorgova core $(34 \mathrm{~cm})$, indicating that these sediments date back to the mid-1950s at the earliest, when ${ }^{137} \mathrm{Cs}$ from atmospheric deposition was first detectable in the northern hemisphere. The unsupported ${ }^{210} \mathrm{~Pb}$ activity and the ${ }^{137} \mathrm{Cs}$ profile also indicate the presence of some bioturbation in that lake. We identified two peaks attributed to the fallout following the Chernobyl accident in 1986 (11.5 $\mathrm{cm}$ ), and to the maximum radionuclide fallout caused by the atmospheric nuclear weapon tests in $1963(21.5 \mathrm{~cm})$. A third peak of ${ }^{137} \mathrm{Cs}$ was measured at $7.5 \mathrm{~cm}$ depth in the Gorgova core. Based on the shape of the peak and after comparison with the lead profile, we concluded that the latter caesium peak probably originated from terrestrial input from the catchment rather than from atmospheric deposition. In Greifensee (Monchamp et al. 2016) and Hallwilersee (Monchamp et al. unpublished data), the two well-resolved ${ }^{137} \mathrm{Cs}$ peaks of 1986 and 1963 (Online Resource 2 in the Supporting Information) correlate well with the model based on annual varve counts. Only minor stratigraphic disturbances were visible within the Gorgova core section, but a high density of mollusc shells fragments were however found in the 
sediments between 19 and $34 \mathrm{~cm}$-depth. Most layers from $18 \mathrm{~cm}$-depth to the surface contained low densities of shell fragments compared to the older sediments (Online Resource 3 in the Supporting Information).

The sedimentations rates were calculated based on ${ }^{137} \mathrm{Cs}$ in all lakes (Table 1) and validated with the ${ }^{210} \mathrm{~Pb}$ measures. The highest sedimentation rate was measured in Lake Gorgova $(0.43 \mathrm{~cm} / \mathrm{yr})$ between 1963 and 1986. The sedimentation rate in Greifensee was relatively stable throughout the period of eutrophication and re-oligotrophication (between 0.30 $-0.34 \mathrm{~cm} / \mathrm{yr}$ ), while in Hallwilersee, the sedimentation rate was higher in the recent sediment layers (yr 1986-2014).

Table 1. Sedimentation rates calculated based on ${ }^{137} \mathrm{Cs}$ in the three lakes

\begin{tabular}{lll}
\hline Lake & Period & $\begin{array}{l}\text { Sedimentation rate } \\
(\mathrm{cm} / \text { year })\end{array}$ \\
\hline Gorgova & $1986-2015$ & 0.40 \\
& $1963-1986$ & 0.43 \\
Greifensee & $1986-2013$ & 0.31 \\
Hallwilersee & $1963-1986$ & 0.34 \\
& $1986-2014$ & 0.30 \\
& $1963-1986$ & 0.20 \\
\hline
\end{tabular}

\section{Compositional change in Daphnia and cyanobacterial assemblages}

The analysis of the time-series reconstructed over the past $\sim 60$ years from sedimentary archives revealed changes in the genetic diversity of Daphnia (egg bank) and the taxonomic composition of cyanobacteria (sedimentary DNA) in the three lakes studied. The abundance and composition of Daphnia genotypes varied over time in all the lakes. Overall, we identified 8 Daphnia taxa (species and hybrid classes) in Lake Gorgova, whereas only 5 were found in each of the pre-alpine lakes. Only few eggs were found in the Gorgova sediment layers dated to the 1950s and the early 1960s ( $n<4$ per $1-\mathrm{cm}$ layer). The majority were assigned to D. cucullata, D. galeata, and their hybrids, and a couple of D. galeata $\times$ cucullata. D. longispina $\times$ cucullata hybrids were found in the oldest sample (Fig. 1). 


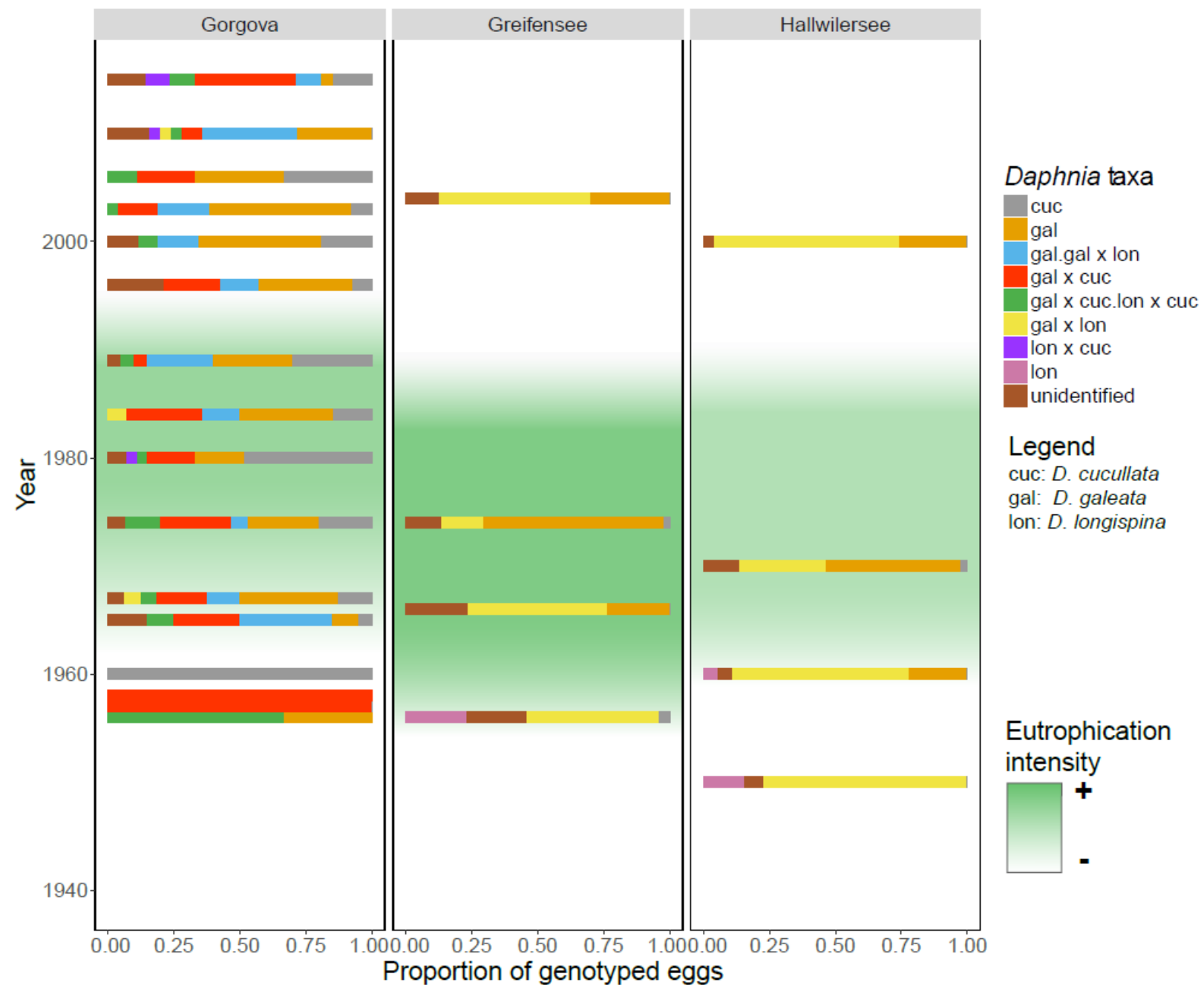

Figure 1. Proportion of Daphnia genotypes in populations reconstructed from ephippial eggs over 7 decades from lake sediment cores. The gradient of green reflects the timing and intensity of the main period of human-induced eutrophication in each lake. Daphnia taxa legend key: cuc, D. cucullata; gal, D. galeata; gal.gal $\times$ lon, D. galeata. D. galeata $\times$ longispina; gal $\times$ cuc, D. galeata $\times$ cucullata; gal $\times$ cuc. lon $\times$ cuc, D. galeata $\times$ cucullata. D. longispina $\times$ cucullata; gal $\times$ lon, D. galeata $\times$ longispina; lon $\times$ cuc, D. longispina $\times$ cucullata $;$ lon, $D$. longispina; unidentified, unidentified.

Between 9 and 26 eggs were found in each of the other sediment layers of Lake Gorgova. D. galeata and their hybrid descendants were generally predominant in the upper half of the core (from 1980 s up to 2014; Fig. 1). The number of eggs retrieved from each sediment layer (each spanning one year) was generally higher in Greifensee (data not available for Hallwilersee), and the number of successfully genotyped eggs ranged from 17 to 47 in the latter two lakes. Eggs assigned to pure D. longispina were only found in samples dated back to the $1950 \mathrm{~s}$ and the $1960 \mathrm{~s}$ in both pre-alpine lakes (Fig. 1). The D. galeata $\times$ longispina hybrid was generally the predominant genotype in the sediments of Hallwilersee and Greifensee, except 
during the 1970s when D. galeata represented the highest proportion of the egg bank in both lakes (Fig. 1).

Similarly to the Daphnia assemblages, the cyanobacterial community composition varied over time in the three lakes. The proportion represented by each cyanobacterial order (based on rarefied 16S rDNA sequence reads) was similar in the two pre-alpine lakes, whereas the reconstructed communities in Gorgova were different from the pre-alpine lakes (Fig. 2).

Filamentous and buoyant taxa in the order Nostocales dominated the community in all samples from Lake Gorgova, whereas small single-celled taxa in the order Synechococcales were predominant in all samples from Greifensee and Hallwilersee. The proportion occupied by OTUs assigned to Nostocales increased in the 1960s and again in the 1990s in both prealpine lakes, especially in Greifensee (Fig. 2). In Gorgova, we observe an increase in the proportion of Chroococcales, which only represented a small percentage of the OTUs until the mid-1970s, and accounted for up to $25 \%$ of the sequence reads after the $1980 \mathrm{~s}$. At the same time in that lake, we observed a decline in the proportion of Nostocales, which were partly replaced by Synechococcales. Because the Synechococcales sequences were highly dominant in all samples in the two pre-alpine, we were unable to visualize the temporal variation in the other cyanobacterial groups, which contain several toxic and bloom-forming taxa. 


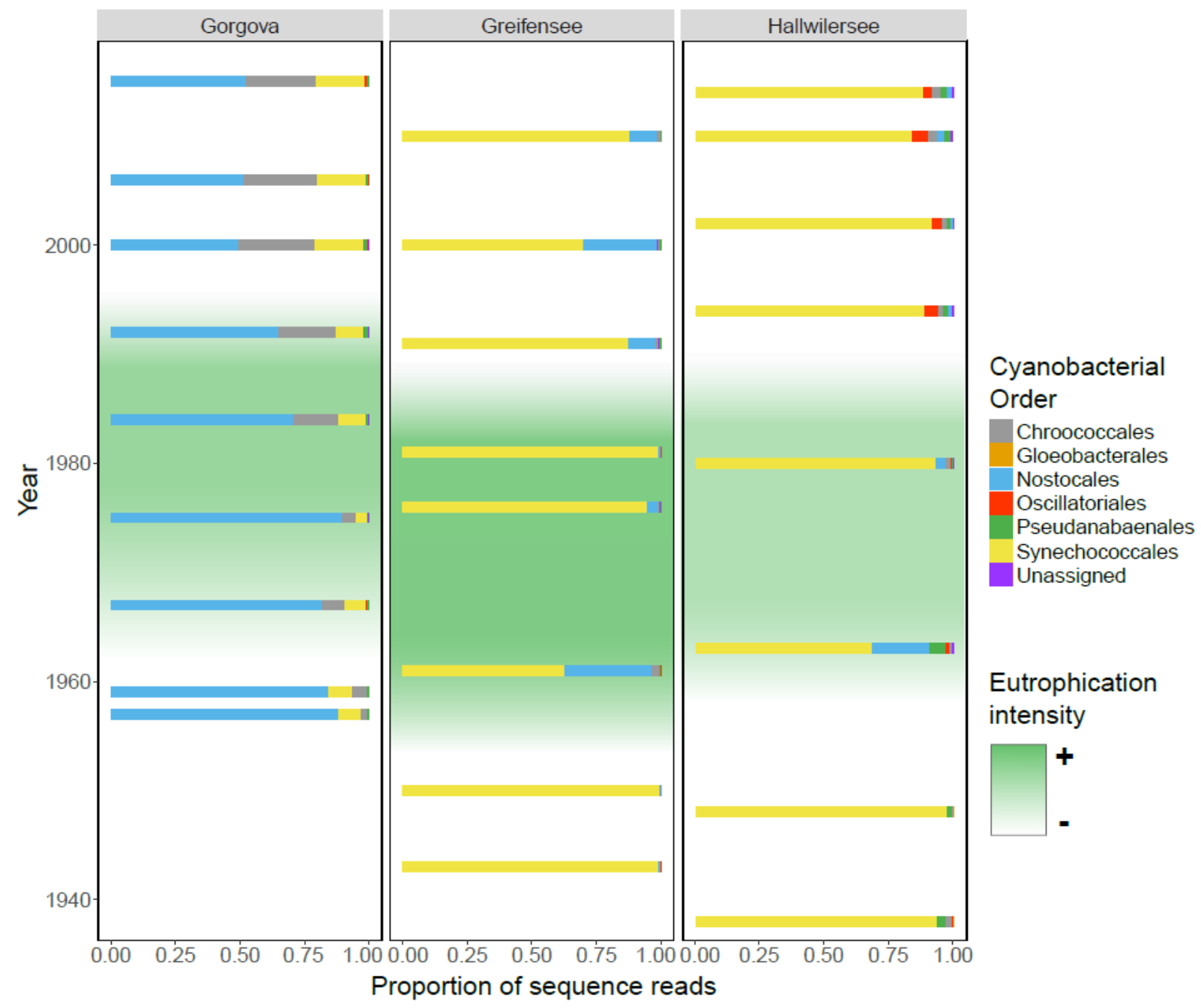

Figure 2. Proportion of rarefied sequence reads assigned to each cyanobacterial order in all samples at the corresponding approximate year reflecting changes in community composition over time in the three lakes. The gradient of green identifies the main period of human-induced eutrophication between the 1950s and the 1980s.

For better visualization of the temporal changes in the potentially harmful cyanobacterial groups, we plotted the proportions of sequence reads within each order, but this time excluding reads assigned to Synechococcales (see Online Resource 4 in the Supporting Information). This plot reveals that the increased in the proportion of OTUs assigned to Nostocales was followed by a decrease in Hallwilersee after the 1980s, and that the Nostocales OTUs were partly replaced by sequences assigned to taxa in the order Oscillatoriales (such as Planktothrix sp. and Phormidium sp.). In Greifensee, the proportion of Nostocales OTUs were the second-most dominant after the Synechococcales, with the exception of one time point in $\sim 1950$ when Chroococcales were slightly more important (Online Resource 4 in the Supporting Information). 
The PCA correlation biplot showed distinct patterns in the distribution of the five cyanobacterial orders and the Daphnia taxa between the Danube Delta lake and the two prealpine lakes, with sites well separated in the ordination space (Fig. 3).

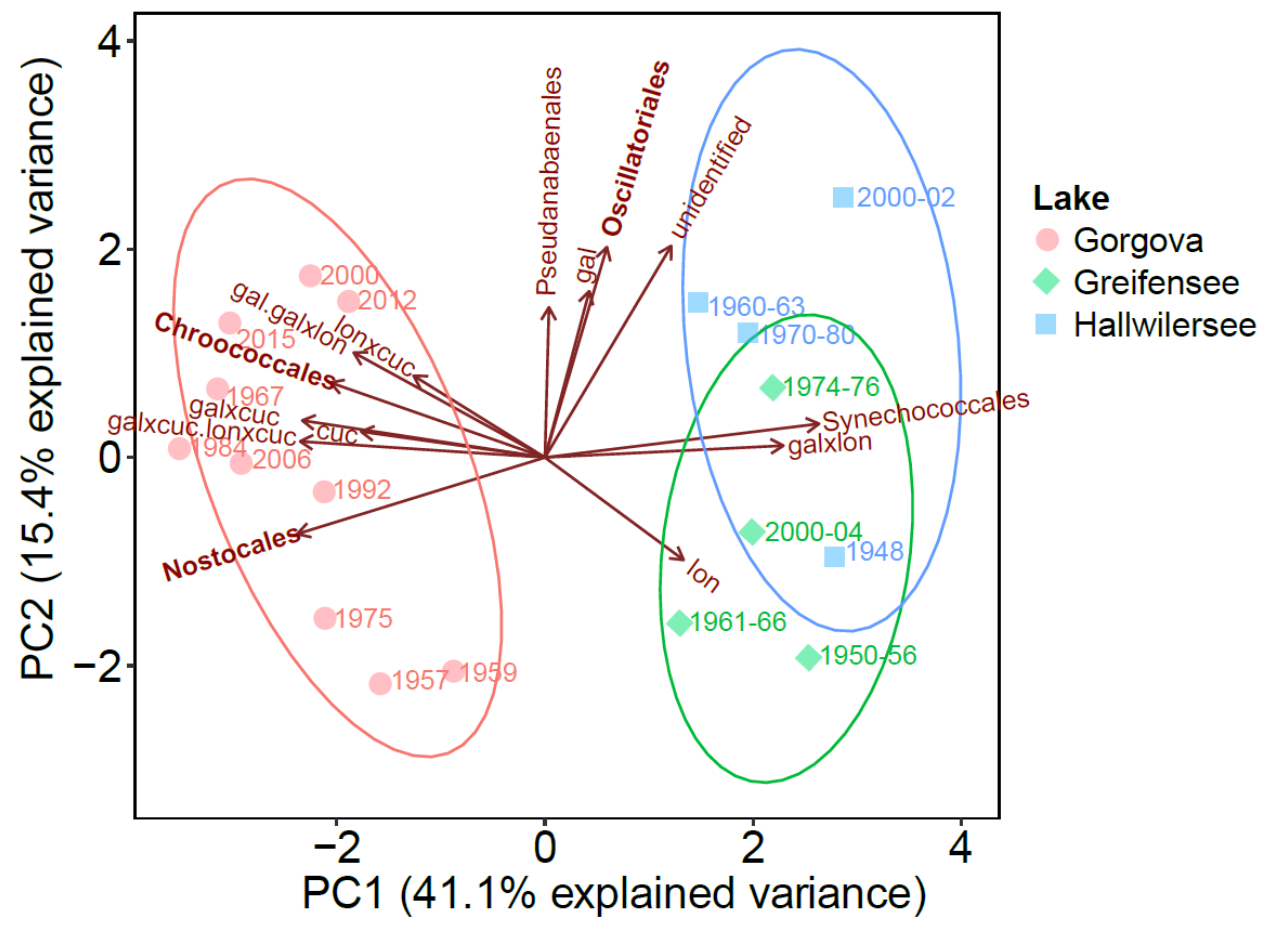

Figure 3. Principal component analysis (PCA) representation based on the proportion of the five main cyanobacterial orders (bloom-forming groups in bold) and the Daphnia community composition in the three lakes over the past 6-7 decades. Ellipses show 85\% confidence intervals. The cyanobacterial 16S rDNA sequence data and the Daphnia genotypic composition analysed at various depths in the sediment cores were grouped and approximate years are used as label coloured by lake. Daphnia taxa legend key: cuc, D. cucullata; gal, D. galeata; gal.gal $\times$ lon, D. galeata. D. galeata $\times$ longispina; gal $\times$ cuc, $D$. galeata $\times$ cucullata; gal $\times$ cuc.lon $\times$ cuc, D. galeata $\times$ cucullata.$D$. longispina $\times$ cucullata; gal $\times$ lon, D. galeata $\times$ longispina; lon $\times$ cuc, D. longispina $\times$ cucullata; lon, D. longispina; unidentified, unidentified Daphnia taxa.

The first axis (PC1) was mainly described by the presence of various D. galeata hybrid classes and a high proportion of the cyanobacterial orders Nostocales, Synechococcales, and Chroococcales, and explained $41.1 \%$ of total variance. The second axis (PC2, 15.4\% of variance explained) was mainly related to Oscillatoriales and Pseudanabaenales, pure $D$. galeata as well as unidentified Daphnia taxa. There was a general trend towards a shift in community composition over time along the vertical axis (PC2) in Lake Gorgova. In Greifensee, the community shifted from a more D. longispina-dominated community to a $D$. galeata $x$ D. longispina-dominated community. All samples from the pre-alpine lakes were characterized by the presence of Synechococcales (Fig. 3). 
Temporal evolution of the genetic divergence in Daphnia and cyanobacterial communities

The historical trends in genetic differentiation among Daphnia populations (Jost's D) and genetic dissimilarity among cyanobacterial communities (Unifrac) in individual lakes are reported in Fig. 4. The stress values for all NMDS configurations based on Jost's $D$ are lower than 0.03 , and are comprised between 0.069 and 0.12 for the NMDS analyses based on Unifrac distances.

In Lake Gorgova, the genetic differentiation between consecutive Daphnia populations was greater in the older samples (Fig. 4a). The position of the samples in the plot indicates that turnover was lower between consecutive samples since the early 1990s. The temporal patterns in genetic distance based on allelic frequency across Daphnia populations reconstructed from the egg banks were similar in the two pre-alpine lakes over the past fifty years. The cyanobacterial phylogenetic diversity in the older samples (before the onset of the main eutrophication event) in Lake Gorgova was the most divergent from all the other communities in that lake (Fig. 4b). In Greifensee, the turnover was lower between consecutive communities of 1961, 1976 and 1981, which correspond to the period of maximal eutrophication in that lake. During and after re-oligotrophication of the lake (in the 1990s and 2000s) the Daphnia genetic diversity did not return to the original pre-eutrophication structure. The cyanobacterial community from 2010, however, was more similar to that of the pre-eutrophication period (1943 and 1950) compared to the ones corresponding to the mid-eutrophication period. In Hallwilersee, the cyanobacterial communities were characterized by a relatively high divergence between 1928 and 1980 and a considerably lower turnover post-eutrophication (1994 to 2014). These patterns in temporal phylogenetic dissimilarity among communities were also reflected in the individual-lake NMDS representations based on Jaccard distances (i.e., taxonomic diversity based on incidence of OTUs; see Online Resource 5 in the Supporting Information). 

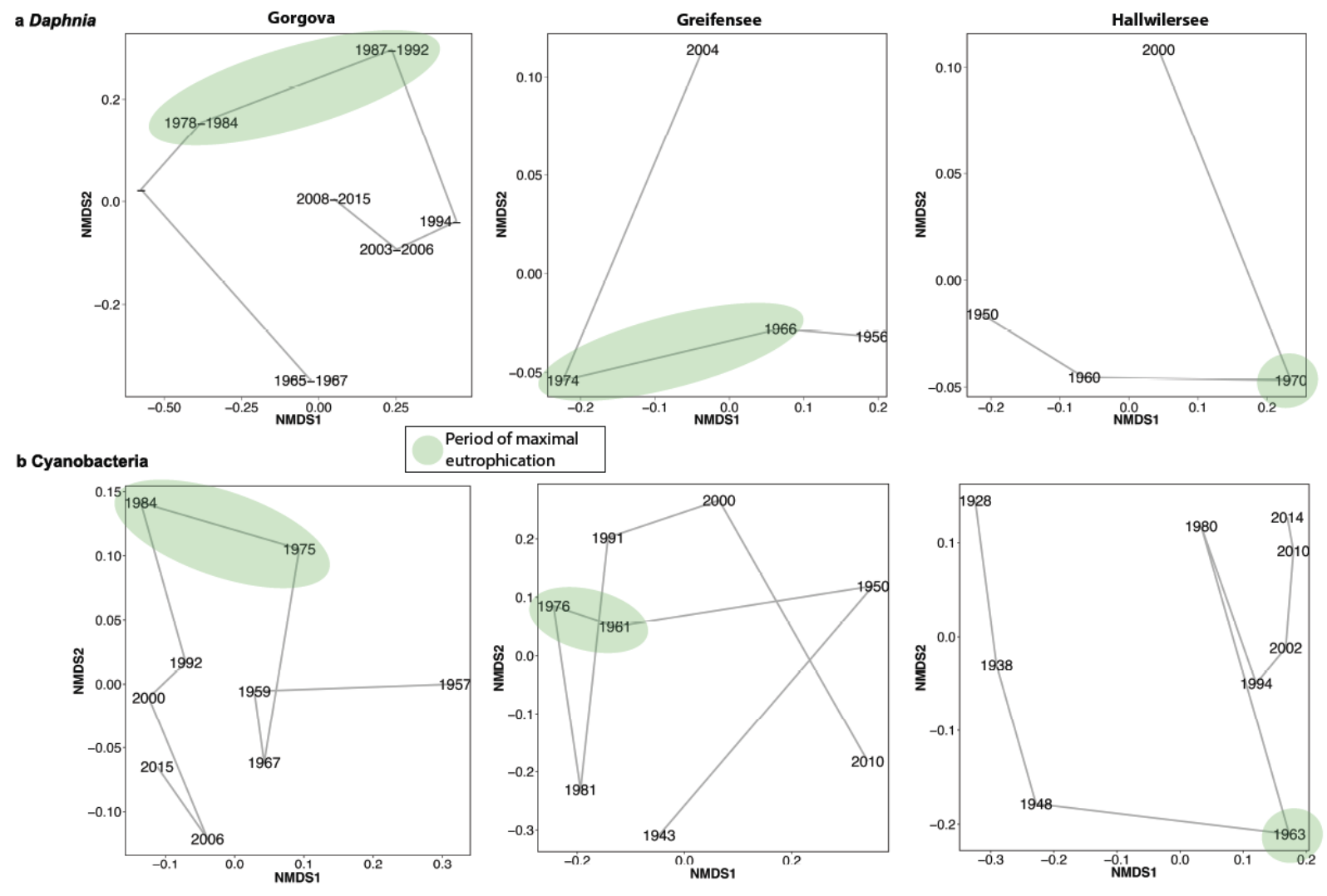

Figure 4. Nonmetric multidimensional scaling (NMDS) representations based on (a) Daphnia genetic distances based on allele frequency, and (b) cyanobacterial phylogenetic dissimilarity (un-weighted Unifrac distances based on incidence of OTUs). The full line between consecutive samples shows the temporal trend in each Daphnia or cyanobacterial community, and samples are labelled using approximate years. The samples corresponding to the period of maximal eutrophication in each lake are highlighted in green.

\section{Detection of potentially microcystin-producing cyanobacteria}

The $m c y A$ gene was detected by PCR in sedimentary DNA samples collected in Gorgova and Greifensee, confirming the presence of potentially toxic cyanobacteria at these sites. In Lake Gorgova, the gene was amplified in twenty-eight out of thirty sediment layers (Fig. 5). Sanger sequencing revealed that all amplicons correspond to a single $m c y A$ sequence assimilated to Microcystis sp. In Greifensee, the $m c y A$ gene was found in only four of the thirteen layers tested spanning the last eight decades. The gene was only found in the top section of the core corresponding to the period between 2000 and 2013. 


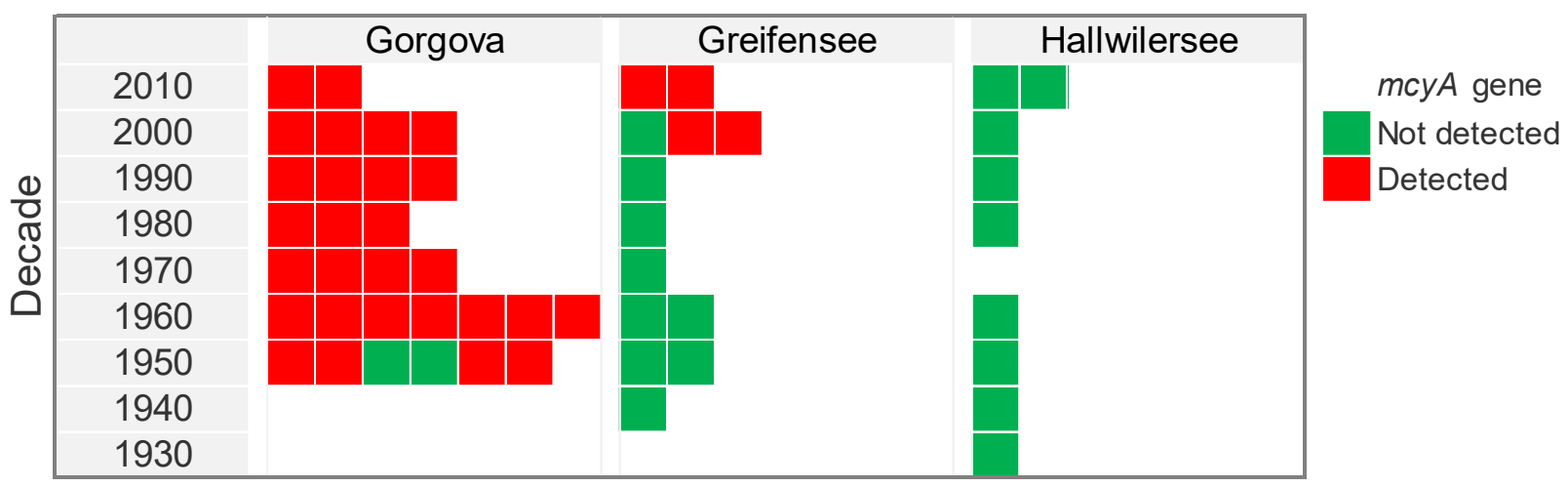

Figure 5. Results of PCR amplifications for the detection of $m c y A$ genes in the sediment cores from lakes Gorgova, Greifensee and Hallwilersee. Each box represents a sample corresponding to an approximate year over the past nine decades. Samples were grouped by decades to simplify visual representation. The samples where $m c y A$ genes were detected are marked in red, whereas a green square signifies that the gene was not detected. The $m c y A$ genes data from the Lake Greifensee sediment core originate from a previous publication (Monchamp et al. 2016).

Surprisingly, the $m c y A$ sequences in Lake Gorgova and Greifensee were all identical, and were identified as a Microcystis sp. (GenBank accession number KX437769.1; This analysis on the Greifensee sediments was done as part of a previous study, see Monchamp et al. 2016). In Hallwilersee, the gene was not detected in any of the nine samples tested spanning between the 1930s and the 2010s. Overall in lakes where the $m c y A$ gene was detected, we found no temporal genetic variation in the composition of the potentially microcystin-producing cyanobacteria.

\section{Discussion}

Here we show that changes in the genetic diversity of Daphnia and the phylogenetic diversity of cyanobacteria, as reconstructed from the sediments of three natural communities over the past 6 to 8 decades, occurred at comparable temporal scales and time periods. Daphnia and cyanobacterial community composition appeared to respond to human-mediated eutrophication. Interestingly, the original composition and genetic structure of the two plankton groups were not restored after re-oligotrophication of the lakes.

Generally, the taxonomic diversity of Daphnia eggs was higher in Lake Gorgova compared to the two pre-alpine lakes. This is mainly because D. cucullata is present in many sediment layers and hybridized with both D. galeata and D. longispina. D. cucullata is a species typical found in eutrophic lakes (Benzie 2005; Flößner 2000). We found that pure D. cucullata and D. galeata were predominant in the eutrophic Lake Gorgova, where filamentous 
cyanobacteria (affiliated mainly to the order Nostocales) were always found in high proportion. These findings are consistent with previous studies having reported that D. galeata thrives in meso- to eutrophic systems, and that $D$. cucullata has a competitive advantage in eutrophic conditions (Benzie 2005; Flößner 2000) and in the presence of filamentous cyanobacteria (DeMott et al. 2001; Gliwicz and Lampert 1990).

In a pilot study done in 2002, Cremer et al. (2004) reconstructed the diatom assemblages from sediment cores collected in Lake Gorgova and from four other lakes located in the Danube Delta. Based on the time-series of diatom composition, it was determined that the lakes were meso- to eutrophic throughout the period covered by the study ( 1920s to 2002), and that most likely, the onset of eutrophication took place in much earlier times in lakes of the Delta. This is not surprising, as the Delta is the end point of the Danube River which has a vast drainage basin and flows through ten countries. Our findings both on the Daphnia and cyanobacterial taxonomic composition in the sediments of Lake Gorgova are consistent with the conclusion of Cremer and colleagues. A few signs in the Gorgova sediment core suggest a drastic change in the ecology of the lake around the 1970s, such as a change in sediment structure and the decline in density of mollusc remains between 18 and $19 \mathrm{~cm}$-depth. These changes most likely reflect rapid modifications of lake conditions (e.g., hypoxia, reduction in the macrophyte coverage) in the late 1960 s and early 1970 s, period which corresponds to the onset of humanmediated eutrophication in the Danube Delta (Rîșnoveanu et al., 2004). At the same time, we observed an increase in the proportion of OTUs assigned to Chroococcales, a group comprising of large colonial taxa that are generally favoured under high nutrient conditions (Sukenik et al. 2015). Interestingly, after the peak of eutrophication in Lake Gorgova (according to the literature on the Danube Delta lakes), there was a slight increase in the proportion of Synechococcales, which could also be an indicator of change in local lake conditions (e.g., nutrient availability). The relative contribution of picocyanobacteria to the total phytoplankton community has been shown to increase with re-oligotrophication (Agawin et al. 2000) due to their low phosphorus requirements. In large and deep water bodies such as pre-alpine lakes, picocyanobacteria are known to account for the majority of the picophytoplankton (reviewed in Callieri 2007).

Our reconstructed time-series of Daphnia populations reflect the species composition reported in previous studies over the past few decades based on pelagic surveys of several lakes located north and south of the European Alps (Keller et al. 2008), and on the egg banks of Greifensee (Brede et al. 2009) and Hallwilersee (Turko et al. 2016). To our knowledge, this constitutes a first report of the Daphnia and cyanobacteria genetic diversity in Lake Gorgova. 
The invasion of D. galeata and the dominance of D. galeata $\times$ longispina hybrids in the prealpine lakes Greifensee and Constance has previously been linked to human-induced eutrophication (Brede et al. 2009). Our results suggest that the Daphnia community in Hallwilersee was similarly affected by local environmental changes leading to the replacement of $D$. longispina by $D$. galeata and their hybrids.

The composition of the Daphnia resting egg bank in Gorgova was different from that of the two pre-alpine lakes, but interestingly, D. galeata and their hybrids were also generally dominant in that lake. We did not find eggs belonging to D. longispina in Gorgova, but hybrids and backcrosses (mostly D. galeata $\times$ cucullata. D. longispina $\times$ cucullata and D. galeata.$D$. galeata $\times$ longispina) signalled the historical presence of D. longispina in the lake. Sampling older sediment layers could reveal an invasion and the subsequent replacement of native taxa by $D$. galeata related to changes in environmental conditions.

The cyanobacterial diversity in the two pre-alpine lakes is known from long-term monitoring data (Bürgi et al. 2003; Bürgi and Jolidon 1998) and from sedimentary DNA reconstructions (Monchamp et al. 2016; Monchamp et al., in prep). The diversity reconstruction over the past few decades in Greifensee confirms the presence of bloom-forming and potentially toxic taxa in the genera Microcystis (order Chroococcales) and Dolichospermum (Anabaena; order Nostocales). In Hallwilersee, we report the presence of Nostocales, as well as OTUs related to Oscillatoriales, including the potentially harmful cyanobacterium Planktothrix rubescens. This particular taxon is known for regularly forming metalimnetic blooms in Hallwilersee (Liechtli 1994) and other pre-alpine lakes north (Posch et al. 2012) and south (D'Alelio et al. 2011) of the Alps. To our knowledge, there are no published reports on the composition of the cyanobacterial assemblage in Lake Gorgova; therefore we are unable to compare our results with other studies. Our compositional data recovered from sedimentary DNA sequencing confirms historical records in Greifensee and Hallwilersee, but as it has been shown before (Monchamp et al. 2016), the number of reads cannot directly be matched to microscopy counts due to biases related to both methods.

Although it is difficult to establish a direct link between the time-series of Daphnia and cyanobacteria reconstructed from natural archives, we can speculate about the temporal trends observed in the composition and diversity of the two plankton assemblages. Interestingly, concomitantly to the major turnover in the Daphnia communities in Greifensee and Hallwilersee, we observed an increase in the proportion of filamentous and bloom-forming cyanobacteria assimilated to order Nostocales in both lakes, and related to Oscillatoriales over 
the past three decades in Hallwilersee. Filamentous cyanobacteria were generally predominant in the sediments of Lake Gorgova over the timespan reflected by our sediment core. There was, however, an increase in the proportion of other colony-forming cyanobacteria (in the order Chroococcales) over the recent few decades. The Daphnia populations of yr 2003-2004 in Greifensee and yr 2000 in Hallwilersee were similar in composition and did not return to the pre-eutrophication population structure, probably as a consequence to the competitive advantage of $D$. galeata in a changing environment due to its broad ecological niche (Weider 1993). D. galeata is also known for investing more in sexual reproduction compared to other species, and to be able to hybridize with almost all other species in the D. longispina complex (Taylor et al. 2005).

The fact that we did not detect the $m c y A$ gene in any samples from Hallwilersee was surprising because the lake's phytoplankton assemblage is known to often comprise a relatively high biomass of Planktothrix rubescens (Liechtli 1994; Züllig 1982), a taxon known to include microcystin-producing strains (Ostermaier and Kurmayer 2010). Our results do not allow us to rule out the possibility that toxic $P$. rubescens genotypes were present in Hallwilersee. Although we were able to detect $P$. rubescens in general, toxic strains may have made up a small part of the population and therefore remained below the detection limit in the sediment layers sampled. As shown in a previous study (Monchamp et al. 2016), the number of sequences derived from sedimentary archives does not always correlate with the abundance of cells in water estimated based on microscopic surveys, probably due to the limitations associated with both methods. An unlikely explanation for the low recovery of Planktothrix rubescens in the sediments could be related to technical aspects of the method, for example low specificity of the PCR primers used or DNA degradation with sediment age. It has however been shown in a previous study using the same approach that a broad range of representatives of the phylum Cyanobacteria, including Planktothrix species, could be recovered from the sediments of prealpine lakes over centuries (Monchamp et al. 2016, Savichtcheva et al. 2011, 2015). In this study, we confirm the presence of an OTU confidently assigned to P. rubescens in Hallwilersee in several sediment samples since the early 1880s, as well as in Lake Gorgova since the 1960s.

\section{Methodological approach and limitations}

One of the main concerns in palaeogenetic studies is related to DNA degradation. The fate of DNA in the sediments depends on various factors, such as temperature, pressure, oxygen concentration, microbial nuclease activity, and adsorption to particles (Boere et al. 2011; 
Coolen and Overmann 1998; Panieri et al. 2010). The cold, dark, and hypoxic to anoxic conditions prevailing at the bottom of the two pre-alpine lakes are favourable for DNA preservation. In the shallow lake Gorgova, the conditions are less ideal (warmer temperatures, mixing). Nevertheless, we were able to recover good quality DNA in high concentration, and amplify 400 nt-long fragments of both the 16S rRNA and the $m c y A$ genes over the relatively recent sediments studied (less than a century old). The sequencing depth and the number of cyanobacterial OTUs in the samples isolated from all lakes were comparable, and we did not detect any patterns that could be attributed to diagenetic processes (e.g. the loss of OTUs with sediment age). We carefully inspected the OTU table and found no evidence for preferential DNA preservation across the cyanobacterial groups.

Many papers have been published that reconstruct past Daphnia populations by genotyping resting eggs from the sediment (Brede et al. 2009; Orsini et al. 2013). Due to the reproductive mode of Daphnia, cyclic parthenogenesis, resting eggs are the outcome of sexual reproduction, thus they reflect the genes present in the population at the moment of production. Daphnia clones that do not reproduce sexually will not be found in the sedimentary archive, but because the final persistence of a Daphnia population is depending on the resting eggs (recovery from catastrophes like strong winters, high temperature or food scarcity), the resting egg bank is a good ecological and evolutionary representation of past populations.

We were able to date the sediment with a yearly resolution in Greifensee and Hallwilersee due to the presence of varves and the lack of mixing in the surface sediments. Lake Gorgova sediments represented a more challenging archive to date, because of multiple mixing events every year, and the shallowness of this lake. Nevertheless, based on ${ }^{137} \mathrm{Cs}$ and ${ }^{210} \mathrm{~Pb}$ activity, we were able to construct an approximate, but robust age model. Our sedimentation rate calculations in the sediments of Lake Gorgova (see Table 1) based on the lead and caesium profiles were in good agreement with previous observations from Cremer et al. (2004), who measured a sedimentation rate of $0.47 \mathrm{~cm} /$ year between 1986 and 2002 and of $0.37 \mathrm{~cm} /$ year between 1963 and 1986 in a core collected in the same lake. We suspected that the upper section of our core, which consisted of relatively aerated and loose sediments, was compressed during transportation of the core to our lab in Switzerland, which could have contributed to underestimate recent sedimentation rates. Nevertheless, the detection of ${ }^{7} \mathrm{Be}$ in the uppermost sediment layer confirmed that the surface sediments were present and we believe that our dating of Lake Gorgova sediments is sufficiently accurate for a coarse reconstruction of past temporal patterns in this lake. 


\section{Conclusion}

In this paper, we report about the diversity of the grazer Daphnia and important primary producers, cyanobacteria, as reconstructed from sediments cores collected in three lakes impacted by human-induced eutrophication over the past century. Our results reveal cooccurring changes in Daphnia and cyanobacterial composition and genetic diversity, most likely as a consequence of human-induced eutrophication. Although it is not possible in this study to infer a causal link between the cyanobacteria and the Daphnia communities, our diversity analyses reveal that $D$. galeata hybrids and filamentous and potentially bloomforming cyanobacteria appear to have been favoured over the past $6-8$ decades in the three eutrophied lakes studied, and importantly, the Daphnia and cyanobacteria assemblages have not returned to the pre-eutrophication composition after the re-oligotrophication phase in the two pre-alpine lakes. Long-term retrospective studies like ours have the potential to help identify the factors governing community assembly of freshwater plankton, and to inform us on how different compartments of the food-web are linked and co-vary in a changing environment.

\section{Acknowledgements}

High-throughput sequencing was performed at Fasteris (Geneva, Switzerland). We thank JeanClaude Walser (Genetic Diversity Centre, ETH Zürich) for bioinformatics support, and Marco Thali (Eawag) for his help with the sequencing library preparation. We very much appreciate the help of Adrian Cacencu, who was our guide in the Danube Delta, and who helped with Lake Gorgova sampling. We also thank Alois Zwyssig (Eawag) for his help with sampling, Nathalie Dubois and Alfred Lück (Eawag) for sampling and sediment dating, Marcin Dziuba, Esther Keller, and Aglaia Pârvu for their help in the lab. Finally, we thank Irene Gregory Eaves for her helpful comments and the two anonymous reviewers for their feedback which greatly improved the manuscript. This work was supported by the Swiss Enlargement Contribution; project IZERZ0 - 142165, "CyanoArchive" to Piet Spaak, in the framework of the RomanianSwiss Research Programme. 


\section{References}

Agawin, N. S. R., C. M. Duarte, \& S. Agustí, 2000. Nutrient and temperature control of the contribution of picoplankton to phytoplankton biomass and production. Limnology and Oceanography 45: 591-600.

Alberto, F., 2009. MsatAllele-1.0: An R package to visualize the binning of microsatellite alleles. Journal of Heredity 100(3):394-397.

Alric, B., M. Möst, I. Domaizon, C. Pignol, P. Spaak \& M. E. Perga, 2016. Local human pressures influence gene flow in a hybridizing Daphnia species complex. J Evol Biol 29:720-735 doi:10.1111/jeb.12820.

Anneville, O., S. Gammeter \& D. Straile, 2005. Phosphorus decrease and climate variability: mediators of synchrony in phytoplankton changes among European peri-alpine lakes. Freshw Biol 50(10):1731-1746.

Benzie, J., 2005. Cladocera: The Genus Daphnia (including Daphniopsis), vol 21. Kenobi Productions, Backhuys Publishers, Ghent. Leiden.

Bissett, A., J. A. E. Gibson, S. N. Jarman, K. M. Swadling \& L. Cromer, 2005. Isolation, amplification, and identification of ancient copepod DNA from lake sediments. Limnology and Oceanography: Methods 3:533-542.

Boere, A. C., J. S. S. Damsté, W. I. C. Rijpstra, J. K. Volkman \& M. J. Coolen, 2011. Source-specific variability in post-depositional DNA preservation with potential implications for DNA based paleoecological records. Organic Geochemistry 42(10):1216-1225.

Bohonak, A. J. \& D. G. Jenkins, 2003. Ecological and evolutionary significance of dispersal by freshwater invertebrates. Ecology letters 6(8):783-796.

Brede, N., C. Sandrock, D. Straile, T. Jankowski, P. Spaak, B. Streit \& K. Schwenk, 2009. The impact of human-made ecological changes on the genetic architecture of Daphnia species. Proceedings of the National Academy of Sciences of the United States of America 106:4758-4763.

Brede, N., A. Thielsch, C. Sandrock, P. Spaak, B. Keller, B. Streit \& K. Schwenk, 2006. Microsatellite markers for European Daphnia. Mol Ecol Notes 6(2):536-539.

Bürgi, H. R., H. Bührer \& B. Keller, 2003. Long-Term Changes in Functional Properties and Biodiversity of Plankton in Lake Greifensee (Switzerland) in Response to Phosphorus Reduction. Aquatic Ecosystem Health \& Management 6(2):147-158 doi:10.1080/14634980301471.

Bürgi, H. R. \& C. Jolidon, 1998. 10 jahre seesanierung Hallwilersee, Die Reaktion des Planktons. Wasser, Energie, Luft 90:109-116.

Callieri, C., 2007. Picophytoplankton in freshwater ecosystems : the importance of small-sized phototrophs. Freshwater reviews 1: 1-28, http://www.bioone.org/doi/abs/10.1608/FRJ-1.1.1.

Capo, E., D. Debroas, F. Arnaud, \& T. Guillemot, 2016. Long-term dynamics in microbial eukaryotes communities : a palaeolimnological view based on sedimentary DNA. Molecular Ecology 25: 5925-5943.

Carey, C. C., B. W. Ibelings, E. P. Hoffmann, D. P. Hamilton \& J. D. Brookes, 2012. Eco-physiological adaptations that favour freshwater cyanobacteria in a changing climate. Water Res 46(5):1394407 doi:10.1016/j.watres.2011.12.016.

Chorus, I. \& J. Bartram, 1999. Toxic cyanobacteria in water: a guide to their public health consequences, monitoring, and management, vol 18. Taylor \& Francis, London.

Coolen, M. J. \& J. Overmann, 1998. Analysis of subfossil molecular remains of purple sulfur bacteria in a lake sediment. Applied and Environmental Microbiology 64(11):4513-4521. 
Cremer, H., A. D. Buijse, A. F. Lotter, W. Oosterberg \& M. Staras, 2004. The palaeolimnological potential of diatom assemblages in floodplain lakes of the Danube Delta, Romania: a pilot study. Hydrobiologia 513(1):7-26 doi:10.1023/B:hydr.0000018158.16862.63.

Cristofor, S., A. Vădineanu \& G. Ignat, 1993. Importance of flood zones for nitrogen and phosphorus dynamics in the Danube Delta. Hydrobiologia 251:143-148.

D’Alelio, D., A. Gandolfi, A. Boscaini, G. Flaim, M. Tolotti \& N. Salmaso, 2011. Planktothrix populations in subalpine lakes: selection for strains with strong gas vesicles as a function of lake depth, morphometry and circulation. Freshw Biol 56(8):1481-1493.

DeMott, W. R., R. D. Gulati \& E. Van Donk, 2001. Daphnia food limitation in three hypereutrophic Dutch lakes: Evidence for exclusion of large-bodied species by interfering filaments of cyanobacteria. Limnology and Oceanography 46(8):2054-2060.

Domaizon, I., O. Savichtcheva, D. Debroas, F. Arnaud, C. Villar, C. Pignol, B. Alric, \& M. E. Perga, 2013. DNA from lake sediments reveals the long-term dynamics and diversity of Synechococcus assemblages. Biogeosciences Discussions 10: 2515-2564.

Drugă, B., P. Turko, P. Spaak \& F. Pomati, 2016. Cyanobacteria Affect Fitness and Genetic Structure of Experimental Daphnia Populations. Environ Sci Technol 50(7):3416-3424 doi:10.1021/acs.est.5b05973.

Edgar, R. C., 2004. MUSCLE: multiple sequence alignment with high accuracy and high throughput. Nucleic Acids Research 32(5):1792-1797.

Faith, D. P., P. R. Minchin \& L. Belbin, 1987. Compositional dissimilarity as a robust measure of ecological distance. Vegetatio 69(1-3):57-68.

Flößner, D., 2000. Die Haplopoda und Cladocera (ohne Bosminidae) Mitteleuropas. Backhuys, Leiden.

Frisch, D., P. K. Morton, P. R. Chowdhury, B. W. Culver, J. K. Colbourne, L. J. Weider \& P. D. Jeyasingh, 2014. A millennial-scale chronicle of evolutionary responses to cultural eutrophication in Daphnia. Ecology letters 17(3):360-8 doi:10.1111/ele.12237.

Ger, K. A., P. Urrutia-Cordero, P. C. Frost, L.-A. Hansson, O. Sarnelle, A. E. Wilson \& M. Lürling, 2016. The interaction between cyanobacteria and zooplankton in a more eutrophic world. Harmful Algae 54:128-144.

Gliwicz, Z. M. \& W. Lampert, 1990. Food thresholds in Daphnia species in the absence and presence of blue-green filaments. Ecology 71:691-702.

Hairston, N. G., C. L. Holtmeier, W. Lampert, L. J. Weider, D. M. Post, J. M. Fischer, C. E. Caceres, J. A. Fox \& U. Gaedke, 2001. Natural selection for grazer resistance to toxic cyanobacteria: Evolution of phenotypic plasticity? Evolution 55(11):2203-2214.

Hairston, N. G., Jr., W. Lampert, C. E. Caceres, C. L. Holtmeier, L. J. Weider, U. Gaedke, J. M. Fischer, J. A. Fox \& D. M. Post, 1999. Lake ecosystems: Rapid evolution revealed by dormant eggs. Nature 401(6752):446-446.

Hisbergues, M., G. Christiansen, L. Rouhiainen, K. Sivonen \& T. Börner, 2003. PCR-based identification of microcystin-producing genotypes of different cyanobacterial genera. Archives of Microbiology 180(6):402-410.

Hou, W., H. Dong, G. Li, J. Yang, M. J. Coolen, X. Liu, S. Wang, H. Jiang, X. Wu \& H. Xiao, 2014. Identification of photosynthetic plankton communities using sedimentary ancient DNA and their response to late-Holocene climate change on the Tibetan Plateau. Scientific reports 4:6648.

Ishida, S., H. Ohtsuki, T. Awano, N. K. Tsugeki, W. Makino, Y. Suyama \& J. Urabe, 2012. DNA extraction and amplification methods for ephippial cases of Daphnia resting eggs in lake sediments: a novel approach for reconstructing zooplankton population structure from the past. Limnology:1-7. 
Jiang, X., H. Gao, L. Zhang, H. Liang \& X. Zhu, 2016. Rapid evolution of tolerance to toxic Microcystis in two cladoceran grazers. Sci Rep 6:25319 doi:10.1038/srep25319.

Jombart, T., 2008. adegenet: a $\mathrm{R}$ package for the multivariate analysis of genetic markers. Bioinformatics 24(11):1403-1405 doi:10.1093/bioinformatics/btn129.

Jost, L., 2008. GST and its relatives do not measure differentiation. Molecular ecology 17(18):40154026.

Keller, B., J. Wolinska, M. Manca \& P. Spaak, 2008. Spatial, environmental and anthropogenic effects on the taxon composition of hybridizing Daphnia. Philosophical Transactions of the Royal Society of London B Biological Sciences 363(1505):2943-2952.

Keller, B., J. Wolinska, C. Tellenbach, \& P. Spaak, 2007. Reproductive isolation keeps hybridizing Daphnia species distinct. 52: 984-991.

Kerfoot, W. C., J. A. Robbins \& L. J. Weider, 1999. A new approach to historical reconstruction: Combining descriptive and experimental paleolimnology. Limnology and Oceanography 44(5):1232-1247.

Lampert, W., 1987. Feeding and nutrition in Daphnia. In Peters, R. H. \& R. De Bernardi (eds) "Daphnia", Memorie dell'instituto di idrobiologia. Memorie dell'instituto di idrobiologia, vol 45, Pallanza, 107-141.

Lampert, W., 2006. Daphnia: Model Herbivore, Predator and Prey. Polish Journal Of Ecology 54(4):607-620.

Lemaire, V., S. Brusciotti, I. van Gremberghe, W. Vyverman, J. Vanoverbeke \& L. De Meester, 2012. Genotype $\times$ genotype interactions between the toxic cyanobacterium Microcystis and its grazer, the waterflea Daphnia. Evolutionary applications 5(2):168-182.

Liechtli, P., 1994. Der Zustand der Seen in der Schweiz, vol 237. Bundesamt für Umwelt, Wald und Landschaft (BUWAL), Bern.

Limburg, P. A. \& L. J. Weider, 2002. 'Ancient' DNA in the resting egg bank of a microcrustacean can serve as a palaeolimnological database. P Roy Soc Lond B Bio 269(1488):281-287.

Lozupone, C. \& R. Knight, 2005. UniFrac: a new phylogenetic method for comparing microbial communities. Applied and environmental microbiology 71(12):8228-8235.

McMurdie, P. J. \& S. Holmes, 2013. phyloseq: an R package for reproducible interactive analysis and graphics of microbiome census data. PLoS One 8(4):e61217 doi:10.1371/journal.pone.0061217.

Monchamp, M. E., J. C. Walser, F. Pomati \& P. Spaak, 2016. Sedimentary DNA reveals cyanobacteria community diversity over 200 years in two peri-alpine lakes. Appl Environ Microbiol doi:10.1128/AEM.02174-16.

Montero-Pau, J., A. Gomez \& J. Munoz, 2008. Application of an inexpensive and high-throughput genomic DNA extraction method for the molecular ecology of zooplanktonic diapausing eggs. Limnology and Oceanography: Methods 6:218-222.

Möst, M., S. Oexle, S. Marková, D. Aidukaite, L. Baumgartner, H. B. Stich, M. Wessels, D. MartinCreuzburg, \& P. Spaak, 2015. Population genetic dynamics of an invasion reconstructed from the sediment egg bank. Molecular Ecology 24: 4074-4093.

Möst, M. H., 2013. Environmental change and its impact on hybridising Daphnia species complexes. Ph.D. Thesis, ETH.

Müller, B., R. Gächter, \& A. Wüest, 2014. Accelerated water quality improvement during oligotrophication in peri-alpine lakes. Environmental Science and Technology 48: 6671-6677.

OECD, 1982. Eutrophication of waters. Monitoring, assessment and control. Final report, OECD cooperative programme on monitoring of inland waters (eutrophication control) Environment Directorate, OECD, Paris. 
Oosterberg, W., A. Buijse, H. Coops, B. Ibelings \& G. Menting, 2000. Ecological gradients in the Danube Delta lakes: present state and man-induced changes. Ministry of Transport, Public Works and Water Management.

Orsini, L., K. Schwenk, L. De Meester, J. K. Colbourne, M. E. Pfrender \& L. J. Weider, 2013. The evolutionary time machine: using dormant propagules to forecast how populations can adapt to changing environments. Trends Ecol Evol 28(5):274-282 doi:DOI 10.1016/j.tree.2013.01.009.

Ostermaier, V. \& R. Kurmayer, 2010. Application of real-time PCR to estimate toxin production by the cyanobacterium Planktothrix sp. Applied and environmental microbiology 76(11):3495-3502.

Paerl, H. W., R. S. Fulton, 3rd, P. H. Moisander \& J. Dyble, 2001. Harmful freshwater algal blooms, with an emphasis on cyanobacteria. TheScientificWorldJournal 1:76-113.

Panieri, G., S. Lugli, V. Manzi, M. Roveri, B. Schreiber \& K. Palinska, 2010. Ribosomal RNA gene fragments from fossilized cyanobacteria identified in primary gypsum from the late Miocene, Italy. Geobiology 8(2):101-111.

Petrusek, A., A. Hobæk, J. P. Nilssen, M. Skage, M. Černý, N. Brede \& K. Schwenk, 2008a. A taxonomic reappraisal of the European Daphnia longispina complex (Crustacea, Cladocera, Anomopoda). Zoologica Scripta 37(5):507-519.

Petrusek, A., J. Seda, J. Machácek, Ruthová \& P. Smilauer, 2008b. Daphnia hybridization along ecological gradients in pelagic environments: The potential for the presence of hybrid zones in plankton. Philosophical Transactions of the Royal Society B: Biological Sciences 363(1505):2931-2941.

Posch, T., O. Koster, M. M. Salcher \& J. Pernthaler, 2012. Harmful filamentous cyanobacteria favoured by reduced water turnover with lake warming. Nature Climate Change 2(11):809-813 doi:10.1038/nclimate1581.

R Core Team, 2013. R: A language and environment for statistical computing. R Foundation for Statistical Computing, Vienna, Austria.

Rellstab, C., B. Keller, S. Girardclos, F. Anselmetti \& P. Spaak, 2011. Anthropogenic eutrophication shapes the past and present taxonomic composition of hybridizing Daphnia in unproductive lakes. Limnology and Oceanography 56(1):292-302 doi:doi:10.4319/lo.2011.56.1.0292.

Rigosi, A., C. C. Carey, B. W. Ibelings \& J. D. Brookes, 2014. The interaction between climate warming and eutrophication to promote cyanobacteria is dependent on trophic state and varies among taxa. Limnology and Oceanography 59(1):99-114.

Rîşnoveanu, G., C. Postolache, A. Vădineanu, 2004. Ecological significance of nitrogen cycling by tubificid communities in shallow eutrophic lakes of the Danube Delta, Hydrobiologia, 524 (1): 193-202, doi 10.1023/B:HYDR.0000036133.92034.69

Rohrlack, T., E. Dittmann, M. Henning, T. Börner \& J.-G. Kohl, 1999. Role of microcystins in poisoning and food ingestion inhibition of Daphnia galeata caused by the cyanobacterium Microcystis aeruginosa. Applied and environmental microbiology 65(2):737-739.

Savichtcheva, O., D. Debroas, R. Kurmayer, C. Villar, J. P. Jenny, F. Arnaud, M. E. Perga \& I. Domaizon, 2011. Quantitative PCR enumeration of total/toxic Planktothrix rubescens and total cyanobacteria in preserved DNA isolated from lake sediments. Appl Environ Microbiol 77(24):8744-53 doi:10.1128/AEM.06106-11.

Savichtcheva, O., D. Debroas, M. E. Perga, F. Arnaud, C. Villar, E. Lyautey, A. Kirkham, C. Chardon, B. Alric, \& I. Domaizon, 2015. Effects of nutrients and warming on Planktothrix dynamics and diversity: A palaeolimnological view based on sedimentary DNA and RNA. Freshwater Biology 60: 31-49.

Schindler, D. W., 2012. The dilemma of controlling cultural eutrophication of lakes. Proc Biol Sci 279(1746):4322-33 doi:10.1098/rspb.2012.1032. 
Schwenk, K., D. Posada \& P. D. N. Hebert, 2000. Molecular systematics of European Hyalodaphnia: the role of contemporary hybridization in ancient species. P Roy Soc Lond B Bio 267(1455):1833-1842.

Schwenk, K. \& P. Spaak, 1995. Evolutionary and ecological consequences of interspecific hybridization in cladocerans. Experientia 51:465-481.

Smith, V. H., 2003. Eutrophication of freshwater and marine ecosystems: a global problem. Environ Sci Pollut Res Int 10:126-139 doi:10.1065/esor2002.12.142.

Smith, V. H., S. B. Joye \& R. W. Howarth, 2006. Eutrophication of freshwater and marine ecosystems. Limnology and Oceanography 51(1 II):351-355.

Stöckli, A., 2010. Dem Hallwilersee geht es immer besser! Umwelt Aargau 49:13-19.

Stoof-Leichsenring, K. R., L. S. Epp, M. H. Trauth \& R. Tiedemann, 2012. Hidden diversity in diatoms of Kenyan Lake Naivasha: a genetic approach detects temporal variation. Mol Ecol 21(8):191830 doi:10.1111/j.1365-294X.2011.05412.x.

Sukenik, A., A. Quesada \& N. Salmaso, 2015. Global expansion of toxic and non-toxic cyanobacteria: effect on ecosystem functioning. Biodiversity and Conservation 24(4):889-908 doi:10.1007/s10531-015-0905-9.

Taylor, D. J., H. L. Sprenger \& S. Ishida, 2005. Geographic and phylogenetic evidence for dispersed nuclear introgression in a daphniid with sexual propagules. Molecular ecology 14(2):525-537.

Toonen, R. J. \& S. Hughes, 2001. Increased throughput for fragment analysis on an ABI Prism ${ }^{\circledR} 377$ automated sequencer using a membrane comb and STRand software. BioTechniques 31(6):1320-1324.

Turko, P., L. Sigg, J. Hollender \& P. Spaak, 2016. Rapid Evolutionary Loss of Metal Resistance Revealed by Hatching Decades-Old Eggs. Evolution 70(2):398-407 doi:10.1111/evo.12859.

Vădineanu, A., S. Cristofor, \& G. Ignat, 1992. Phytoplankton and submerged macrophytes in the aquatic ecosystems of the Danube Delta during the last decade. Hydrobiologia 243-244: 141146.

von Elert, E., D. Martin-Creuzburg \& J. R. Le Coz, 2003. Absence of sterols constrains carbon transfer between cyanobacteria and a freshwater herbivore (Daphnia galeata). P Roy Soc Lond B Bio 270(1520):1209-1214 doi:DOI 10.1098/rspb.2003.2357.

Vonlanthen, P., D. Bittner, A. G. Hudson, K. Young, R. Müller, B. Lundsgaard-Hansen, D. Roy, S. Di Piazza, C. R. Largiader \& O. Seehausen, 2012. Eutrophication causes speciation reversal in whitefish adaptive radiations. Nature 482:357-362.

Weider, L. J., 1993. Niche breadth and life history variation in a hybrid Daphnia complex. Ecology 74:935-943.

Winter, D. J., 2012. MMOD: an R library for the calculation of population differentiation statistics. Mol Ecol Resour 12(6):1158-60 doi:10.1111/j.1755-0998.2012.03174.x.

Zolitschka, B., 2007. Varved lake sediments. In Elias, S. A. (ed) Encyclopedia of Quaternary Science. Elsevier, Oxford, 3105-3114.

Züllig, H., 1982. Untersuchung über die Stratigraphie von Carotinoiden im geschichteten Sediment von 10 Schweizer Seen zur Erkungung früherer Phytoplankton-Entfaltungen. Schweiz Z Hydrol 44(1):1-98. 
Chapter III. Electronic Supplementary material

Sedimentary and egg-bank DNA from 3 European lakes reveal concurrent changes in the composition and diversity of cyanobacterial and Daphnia communities

Marie-Eve Monchamp, Ioana Enache, Patrick Turko, Francesco Pomati, Geta Rîșnoveanu, Piet Spaak

Online Resource 1. Summary of the lakes physical, morphological, and chemical characteristics.

\begin{tabular}{llll}
\hline Lake & Gorgova & Greifensee & Hallwilersee \\
\hline Elevation (m.a.s.1.) & 1 & 435 & 449 \\
Maximal depth $(\mathrm{m})$ & $\sim 3$ & 33 & 46 \\
Lake surface area $\left(\mathrm{km}^{2}\right)$ & 13.8 & 8.5 & 10 \\
TP $(\mu \mathrm{g} / \mathrm{L}) *$ & 26 & 40 & 18 \\
TP Max $(\mu \mathrm{g} / \mathrm{L})$ & NA & 492.43 & 213.81 \\
Presence of submerged & Yes & No & No \\
macrophytes & & & Monomictic or incomplete \\
& & & mixing (hypolimnion \\
Water mixing & polymictic & monomictic & mechanically aerated since \\
& & & $1986)$ \\
\hline
\end{tabular}

* Refers to the recent total phosphorus concentrations

${ }^{\text {\# }}$ Refers to the maximum annual mean TP concentration at the peak of eutrophication 


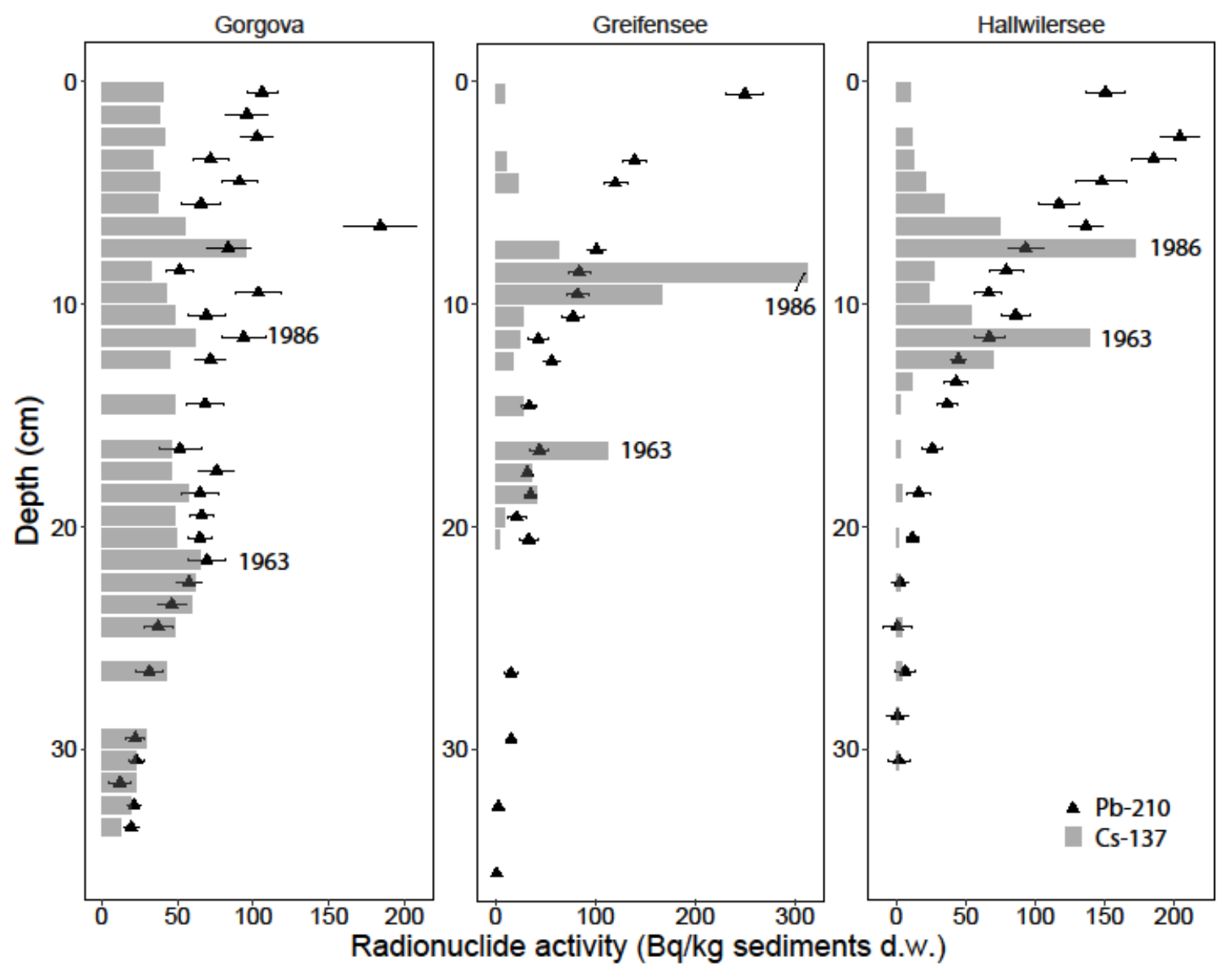

Online Resource 2. Profile of lead-210 activity in the sediments of lakes Gorgova, Greifensee, and Hallwilersee. The dashed lines show the position of the caesium-137 peaks in the cores. The upper line represents the fallout after the Chernobyl accident of 1986, and the lower line shows the peak from the maximum fallout after the nuclear tests in 1963. 


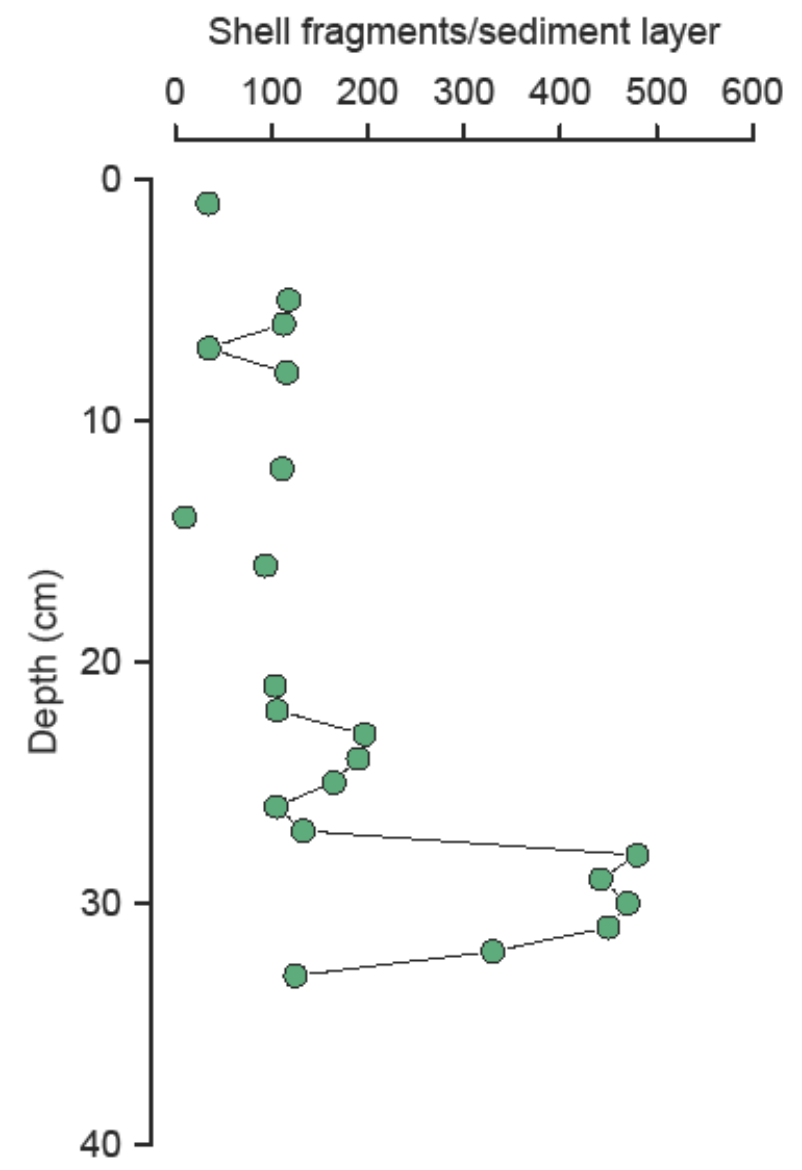

Online Resource 3. Profile of the mollusc shell fragments counted per 1-cm layer in the Gorgova sediment core. 


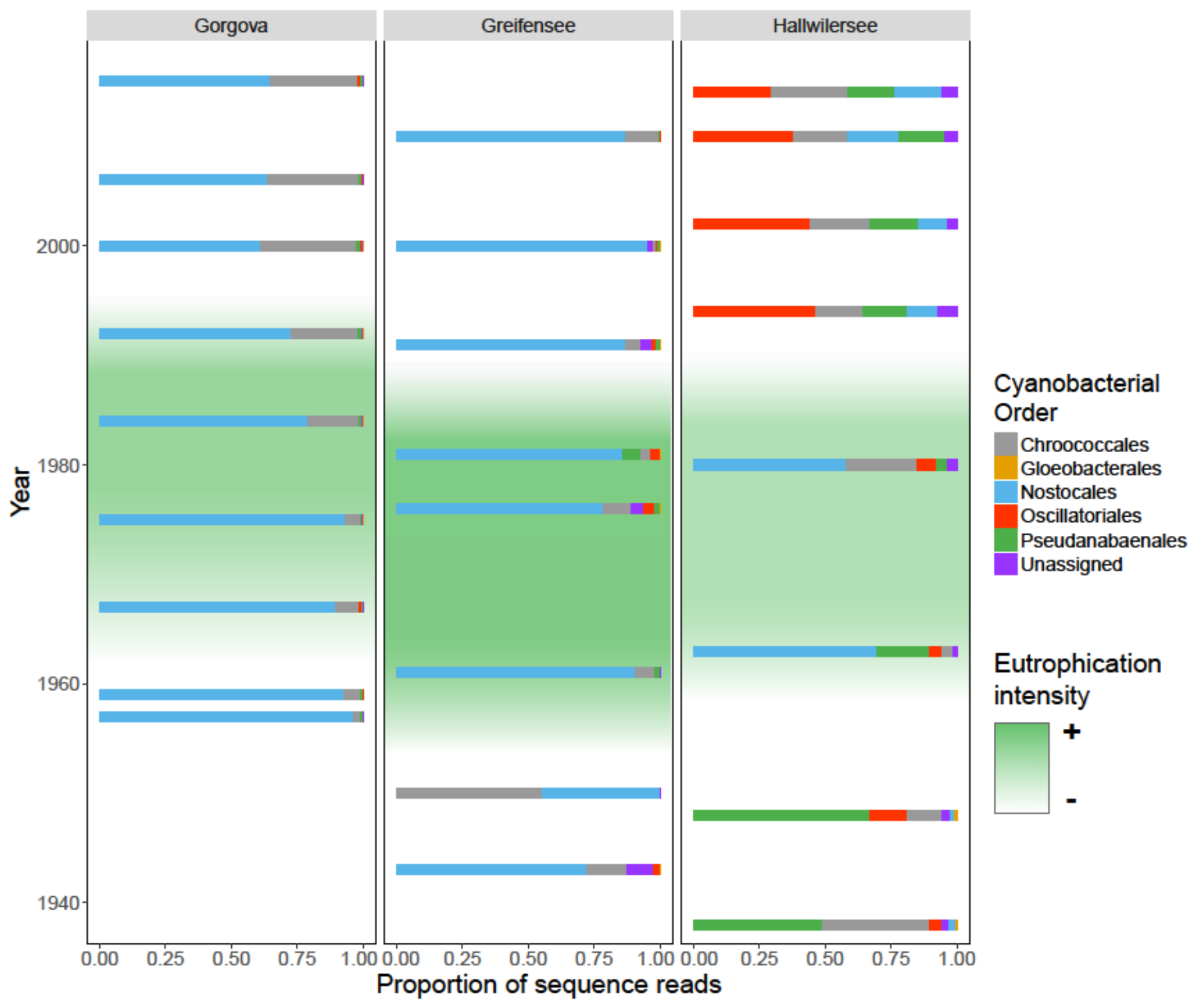

Online Resource 4. Proportion of rarefied sequence reads assigned to each cyanobacterial order excluding order Synechococcales in all samples at the corresponding approximate year reflecting changes in community composition over time in the three lakes. The gradient of green identifies reflects the intensity of the main period of human-induced eutrophication in each lake. 

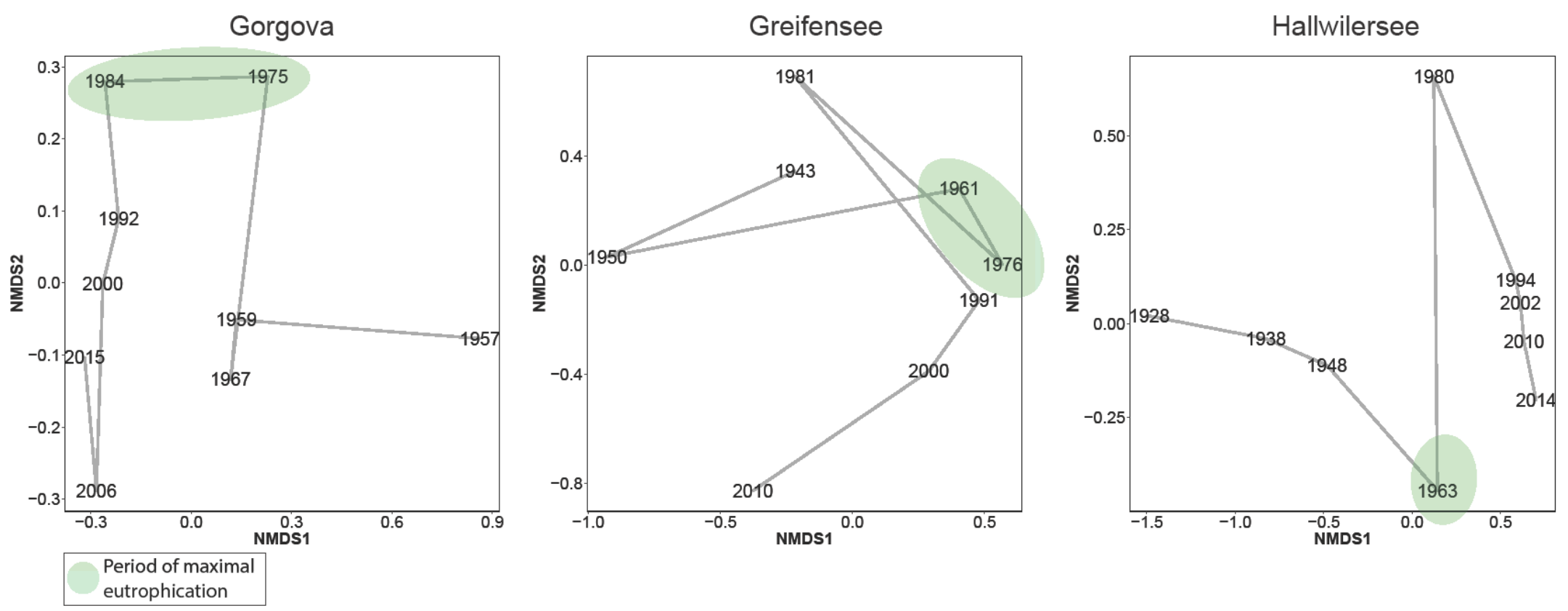

Online Resource 5. Nonmetric multidimensional scaling (NMDS) representations based on taxonomic dissimilarity (Jaccard distances, based on OTU incidence) across cyanobacterial communities within each lake over time. The line connects consecutive sample to show the temporal trajectory of the cyanobacterial communities composition.

\section{Supplementary Information References:}

Monchamp, M. E., J. C. Walser, F. Pomati \& P. Spaak, 2016. Sedimentary DNA reveals cyanobacteria community diversity over 200 years in two peri-alpine lakes. Applied and Environmental Microbiology 82:6472-6482 doi:10.1128/AEM.02174-16. 